\title{
Técnicas de microscopía electrónica usadas en el estudio de nanopartículas*
}

\section{Electron microscopy techniques used in the study of nanoparticles}

\author{
Francisco Paraguay-Delgado**
}

\begin{abstract}
The phenomena involved in the interaction between electrons and matter are suitable signals for the study of nanoparticles. Each type of interaction is explained to know in detail the characteristics of nanomaterials such as: shape, size, crystallinity and composition. This work briefly describes the architecture and specific characteristics of three transmission electron microscopes, with the aim of demonstrating how the physical properties of nanomaterials can be studied and determined using techniques related to these instruments. A systematic and detailed study of two types of nanoparticles is also presented, specifically interpreting each experimental results obtained with different capacities of each electron microscopes used. The methodologies exposed in the materials characterization are reinforced with the inclusion of diverse nanomaterials studies.
\end{abstract}

KEYWORDS: electron microscopy, nanomaterials, nanotechnology, electron diffraction, semiconductor oxides.

RESUMEN: Los fenómenos involucrados en la interacción de electrones con la materia son señales adecuadas para el estudio de nanopartículas. Se explica cada tipo de interacción para conocer en detalle las características de los nanomateriales como: la forma, el tamaño, la cristalinidad y la composición. En este trabajo, se describen brevemente la arquitectura y las características específicas de tres microscopios electrónicos de transmisión con el objetivo de demostrar cómo se puede estudiar y determinar las propiedades fisicas de los nanomateriales utilizando técnicas involucradas con estos instrumentos. También se presenta un estudio sistemático y detallado de dos tipos de nanopartículas, interpretando específicamente cada resultado experimental obtenido con diferentes capacidades de cada microscopio electrónico utilizado. Se refuerzan las metodologías expuestas en la caracterización de los materiales incluyendo, como ejemplos, varios estudios de nanomateriales

PALABRAS CLAVE: microscopio electrónico, nanomateriales, nanotecnología, difracción de electrones, óxidos semiconductores.

Recibido: 10 de febrero de 2020.

Aceptado: 30 de abril de 2020.

* Agradezco a los colegas del NaNoTeCh-CIMAV, a los estudiantes de doctorado que tuve y tengo, quienes me han ayudado para avanzar y terminar esta contribución. Gracias a la Dra. Mou Pal por facilitar las muestras A y B. También gracias a mis hijas Fabiola y Gabriela por dedicarle tiempo en revisar la redacción, haciendo este trabajo cada vez más entendible.

** Laboratorio Nacional de Nanotecnología ( $\mathrm{NaNoTeCh}$ ): Centro de Investigación en Materiales Avanzados SC. (CIMAV). Miguel de Cervantes 120, complejo industrial Chihuahua, CP 31136 Chih. México.

Correo electrónico: francisco.paraguay@cimav.edu.mx 


\section{Introducción}

Los sistemas ópticos son instrumentos formados con más de una lente con propósitos específicos, tanto para ver objetos microscópicos (microscopios) como para objetos alejados como planetas o galaxias (telescopios). Las lentes pueden ser para luz (fotones) o para partículas cargadas (electrones, iones, etc.). En el caso de las partículas cargadas, las lentes están basadas en campos eléctricos y campos magnéticos generados por cargas eléctricas e imanes, respectivamente. De forma general, los sistemas ópticos se conforman con diferentes radiaciones cuyas longitudes de onda para luz visible (4000 y $8000 \AA$ ): neutrones $(1.5$ a $5 \AA$ ): rayos-X $(1.5 \AA)$ : iones y electrones (menores a $0.01 \AA$ ). Con cada tipo de radiación mencionada se pueden construir microscopios, para ello es necesario "guiar o direccionar" la radiación respectiva, es decir, juntar o expandir (este proceso lo hacen las lentes). Entonces en la mayoría de las radiaciones usadas para construir microscopios es posible desviar con facilidad y en otras con mayor dificultad.

De allí la importancia de elegir la radiación adecuada para construir microscopios. Usar iones o electrones proporciona una gran facilidad debido a que son cargas eléctricas, estas partículas cargadas se pueden direccionar con campos electromagnéticos, construyendo lentes electrostáticas y/o magnéticas para, finalmente, ensamblar estas lentes una tras otra hasta construir los microscopios. Actualmente, hay microscopios comerciales construidos con iones (Galio $\mathrm{Ga}^{+3}$, Helio $\mathrm{He}^{+2}$ ) y electrones $\left(\mathrm{e}^{-}\right.$): cada uno de ellos para propósitos específicos. En el caso de los microscopios electrónicos (usan radiación de electrones): la longitud de onda con la que trabajan depende específicamente del voltaje de aceleración y de la configuración de las lentes magnéticas. Ya sea para iluminar con haces casi paralelos (modo de transmisión) o para rastrear con un haz cónico (escaneo en modo de transmisión): en ambos casos los electrones atraviesan la muestra tal como se indica en la figura 1.

Los microscopios construidos con radiación de electrones son de gran utilidad para el estudio de materiales en la actualidad. Una de las ventajas es que los electrones, debido a su carga y energía tienen una fuerte interacción con los átomos que conforman el material en estudio (muestra). Este es un mecanismo útil para conocer las características del nanomaterial. Los fenómenos que ocurren son similares al que sucede en el experimento con el que Rutherford descubrió el núcleo del átomo. ${ }^{1}$ De forma similar, en los microscopios electrónicos al lanzar electrones sobre el material en estudio, detectaremos electrones transmitidos, desviados y radiaciones electromagnéticas. A diferencia de la tecnología usada por Rutherford (película fotográfica): la ventaja que tenemos ahora es que existen detectores de electrones (cámaras digi-

\footnotetext{
${ }^{1}$ Experimento de Rutherford. En el que, al hacer incidir un haz de partículas alfa sobre una lámina de oro, se dio cuenta de que el núcleo atómico desvía las partículas alfa en distintas direcciones.
} 
Figura 1. Esquemas de las formas de iluminar a la muestra con: a) haz casi paralelo (modo transmisión), y, b) haz cónico (escaneo en modo transmisión).

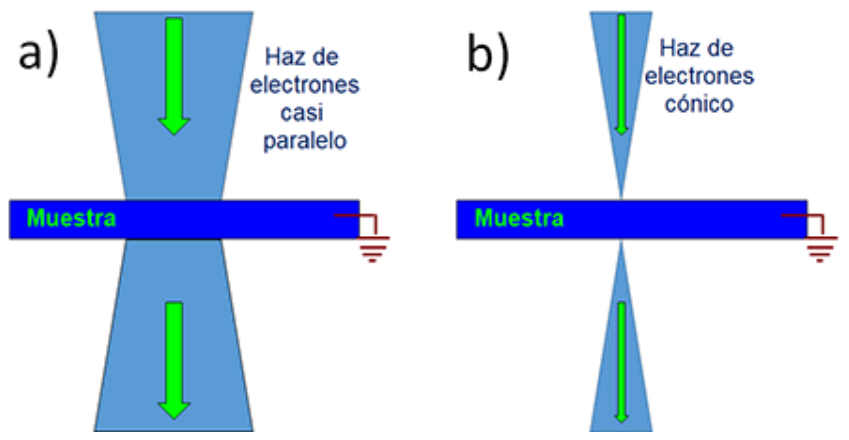

Fuente: Elaboración del autor.

tales) con alta sensibilidad para registrar en forma de imagen todos los electrones desviados, con lo cual obtenemos un resultado más completo acerca de la dispersión de electrones en diferentes direcciones. Luego, al interpretar los resultados experimentales (imágenes) entenderemos el material en estudio de forma específica y clara.

Con este propósito, en este trabajo se dará una explicación concreta de los microscopios electrónicos de transmisión y sus características principales. Luego se interpretan las imágenes obtenidas para conocer cada tipo de material nanométrico en estudio.

\section{Descripción de la arquitectura básica de los microscopios electrónicos de transmisión}

Los microscopios electrónicos están compuestos de varios sistemas para funcionar adecuadamente. Los principales son: sistema óptico, alto voltaje, fuente de electrones, vacío en la columna, refrigeración, sistema electrónico y detectores. El sistema óptico sirve para formar las imágenes, este es el proceso fundamental en la microscopía por eso se explicará en detalle la forma en la que viajan los electrones por las diferentes partes de la columna, en la literatura a esta parte se le denomina óptica-electrónica. Entender con claridad este sistema es de importancia, para interpretar los resultados experimentales - las imágenes obtenidas - que se generan por la interacción del haz de electrones con la muestra.

En la figura 2 se muestra el sistema óptico (columna) de tres microscopios electrónicos de transmisión (MET) que se encuentran en el Laboratorio Nacional de Nanotecnológia (NaNoTeCh) del CIMAV. ${ }^{2}$ La figura 2d muestra el esquema de las lentes electromagnéticas que están agrupadas en tres: sistema

\footnotetext{
${ }^{2}$ https://ntch.cimav.edu.mx/
} 
Figura 2. Sistema óptico de los MET. a) CM200 Philips; b) HT7700 Hitachi; c) JEM2200FS Jeol, y, d) esquema general del MET mostrando sistema de iluminación, objetivo y magnificación.

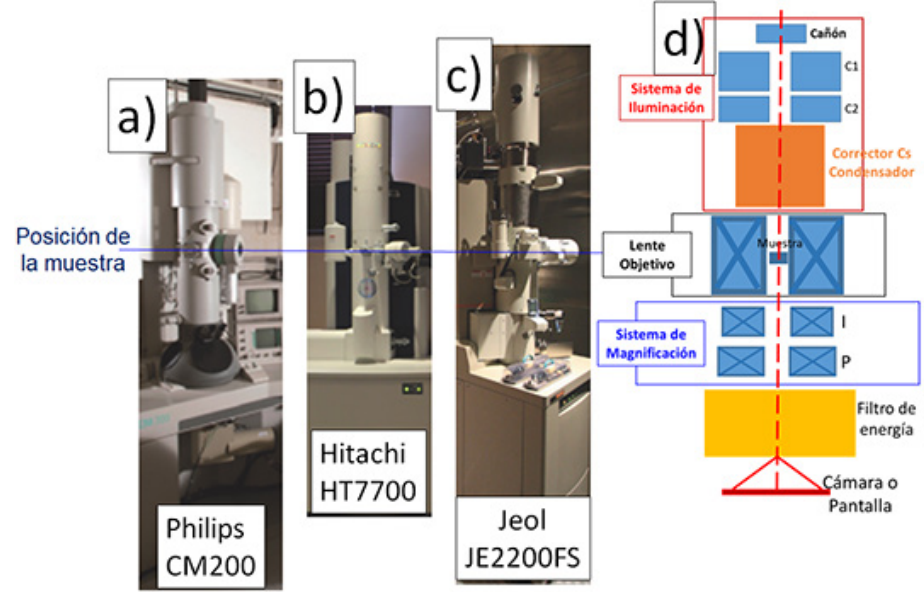

Fuente: Elaboración del autor, imágenes de los equipos de Nanotech, CIMAV, Chihuahua.

de iluminación, formación de imagen (lente objetiva) y sistema de magnificación. Además, cada sistema puede mejorar añadiendo correctores. Por ejemplo, en el sistema de iluminación se puede incluir un monocromador para uniformizar la energía de los electrones incidentes $(C c)$ y/o corrector de aberración esférica (Cs) - para mejorar el enfoque del haz de electrones, haciéndole más intenso y delgado. También se puede añadir un filtro de energía en el sistema de magnificación para separar los electrones emergentes de la muestra en función de su energía. En la figura 2, vemos que los tres microscopios provienen de distintas marcas comerciales. Por consiguiente, presentan configuraciones diferentes en cada columna, las diferencias principales entre ellos se muestran en la tabla 1. Desde el punto de vista de la utilidad para la investigación, estos equipos son complementarios entre ellos ya que no todos tienen los mismos elementos en la columna. La línea horizontal en la parte media de la figura 2, representa la posición de la muestra en cada instrumento. Por tanto, la parte superior de la muestra se llama sistema de iluminación, esta parte está diseñada para lanzar los electrones sobre la muestra. La parte media donde se encuentra la muestra es la parte más importante de cada microscopio y se denomina lente objetivo, aquí se forman las imágenes debido a la interacción del haz de electrones con la muestra. Finalmente, a toda la parte inferior después del lente objetivo se le denomina sistema de magnificación, aquí se amplía en cascada la imagen para obtener un tamaño final más grande a través de las diferentes lentes y, si tiene filtro de energía, este separará los electrones en función de su energía para obtener una imagen con mejor resolución. A continuación, se describirá con más detalle cada uno de estos sistemas ópticos del MET. 
Tabla 1. Diferencias entre los tres MET del CIMAV-NaNoTeCH. Se incluye el año de instalación y procedencia en la primera columna.

\begin{tabular}{|c|c|c|c|c|c|c|}
\hline$\frac{0}{8}$ & 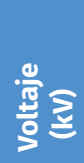 & $\begin{array}{l}\frac{9}{2} \\
\frac{1}{E} \\
\frac{10}{10}\end{array}$ & 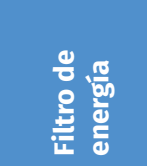 & 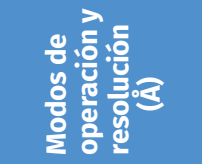 & 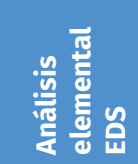 & $\begin{array}{l}y \\
\frac{8}{8} \\
\frac{8}{8} \\
\frac{8}{0}\end{array}$ \\
\hline $\begin{array}{l}\text { CM200 } \\
\text { Philips } \\
1996 \\
\text { Holanda }\end{array}$ & 200 & $\mathrm{LaB}_{6}$ & $\begin{array}{l}\text { después } \\
\text { de columna } \\
\text { DIGI PEELS } \\
766\end{array}$ & $\begin{array}{l}\text { MET } \\
\text { entre líneas } 1.8 \\
\text { entre puntos } 2.5 \\
\text { STEM } \\
\text { BF } 50\end{array}$ & $\begin{array}{l}\text { EDAX } \\
\text { USA }\end{array}$ & $\begin{array}{l}\text { Placa } \\
\text { fotográfica } \\
\text { BF } \\
\text { DF }\end{array}$ \\
\hline \multirow[t]{2}{*}{$\begin{array}{l}\text { JEM2200FS } \\
\text { Jeol } \\
2009 \\
\text { Japón }\end{array}$} & 200 & $\begin{array}{l}\text { Emisión de } \\
\text { campo tipo } \\
\text { Schottky }\end{array}$ & $\begin{array}{l}\text { en columna } \\
\text { tipo } \\
\text { Omega }\end{array}$ & $\begin{array}{l}\text { MET } \\
\text { entre líneas } 1 \\
\text { entre puntos } 1.8 \\
\text { STEM } \\
\text { BF } 1.36 \\
\text { HAADF } 1\end{array}$ & $\begin{array}{l}\text { Oxford } \\
\text { Inglaterra }\end{array}$ & $\begin{array}{l}\text { Cámara } \\
\text { digital } \\
\text { OneView } \\
\text { (Gatan) } \\
\text { BF } \\
\text { HAADF }\end{array}$ \\
\hline & \multicolumn{6}{|c|}{ Este equipo tiene corrector de aberración esférica en el modo STEM. } \\
\hline \multirow[t]{2}{*}{$\begin{array}{l}\text { HT7700 } \\
\text { Hitachi } \\
2015 \\
\text { Japón }\end{array}$} & 120 & $\mathrm{LaB}_{6}$ & No & $\begin{array}{l}\text { MET } \\
\text { entre líneas } 2 \\
\text { entre puntos } 2.9 \\
\text { STEM } \\
\text { BF = HAADF } 15\end{array}$ & $\begin{array}{l}\text { Bruker } \\
\text { Alemán }\end{array}$ & $\begin{array}{l}\text { Cámara } \\
\text { digital } \\
\text { AMT sCMOS } \\
\text { BF } \\
\text { HAADF }\end{array}$ \\
\hline & \multicolumn{6}{|c|}{$\begin{array}{l}\text { Este equipo tiene una lente objetiva Hexalens, se configura automáticamente para } \\
\text { estudiar muestras biológicas (alto contraste) y materiales. }\end{array}$} \\
\hline
\end{tabular}

EDS: Energy Dispersive Spectroscopy.

PEELS: Parallel Electron Energy Loss Spectroscopy.

BF: Bright Field.

DF: Dark Field.

STEM: Scanning Transmisión Electron Microscope.

Fuente: Elaboración del autor.

Sistema de iluminación. Como se mencionó, este sistema está configurado para extraer, acelerar, expandir, juntar, hacer paralelo o cónico el haz de electrones y dosificar la incidencia sobre la muestra. El sistema básico consta del cañón de electrones, zona de aceleración, lentes condensadoras ( $\mathrm{C} 1$ y C2) y las bobinas deflectoras (para más detalle ver manual de cada instrumento). Opcionalmente, puede tener monocromador de energía o corrector de aberración esférica (Cs). En este sistema la fuente de electrones puede ser desde un filamento de tungsteno, cristal de hexaboruro de Lantano $\left(\mathrm{LaB}_{6}\right)$ o emisión de electrones por campos eléctricos desde un filamento súper-puntiagudo de tungsteno recubierto por óxido de zirconio a diferentes temperaturas.

Lente objetivo. Es el sistema que forma la primera imagen de la muestra y el patrón de difracción en el plano imagen y en el plano focal, respectivamente. Esta lente es configurable con el suministro de la corriente para tra- 
bajar como una lupa o como una lente condensadora, dependiendo del propósito deseado. Es decir, podemos configurar al mismo equipo para distintos propósitos específicos. Algunos equipos tienen corrector de aberración esférica para esta lente (no es el caso de $\mathrm{NaNoTeCh}$ ).

Sistema de magnificación. Esta parte del MET está formada por lentes intermedias (I), lentes proyectoras (P) y bobinas deflectoras. También, de acuerdo con el interés del usuario, en esta parte se seleccionará la imagen o el patrón de difracción. Entonces, si queremos ver la imagen (formada en plano imagen de la lente objetiva) estas lentes amplían la imagen en cascada sin perder la resolución. Por otro lado, si queremos ver o registrar el patrón de difracción (formado en el plano focal de la lente objetiva) también magnifica manteniendo la resolución. Pero de acuerdo con la selección, el usuario podrá ver la imagen o patrón de difracción en la parte final del sistema óptico (cámara, figura 2d).

En el caso del filtro de energía, dos microscopios del CIMAV incluyen, uno en columna (JEM2200FS) y el otro en pos-columna (CM200 solo espectroscopía). Esta parte del instrumento, clasifica los electrones que atravesaron la muestra en función de su energía. Luego, el usuario elige las zonas del espectro para mejorar la calidad de las imágenes, determinar el plasmón, energía de enlace, entre otras de las muestras en estudio (Egerton, 2011).

\section{Interacción del haz de electrones con la muestra}

Los electrones que inciden sobre la muestra interactúan a nivel atómico con los elementos químicos que conforman. Entonces los resultados que obtendremos serán solamente de la zona de interacción y sus vecindades cercanas. Por consiguiente, el resultado que deseamos saber dependerá de la zona y forma de hacer incidir los electrones sobre la muestra (figura 1); para este propósito se usa el sistema de iluminación. Por ejemplo, en el caso de nanomateriales es de mucho interés obtener información de una sola nanopartícula (NP) o solo de alguna zona de esta. Como los nanomateriales son menores a $100 \mathrm{~nm}$ (100 millonésima parte de milímetro): entonces nuestro sistema de iluminación del haz de electrones debe generar haces paralelos o cónicos cuyos diámetros sean menores a $100 \mathrm{~nm}$ y $1 \AA$ A sobre la muestra, respectivamente.

Las principales interacciones del haz de electrones incidentes con la muestra se describen en la figura 3. En esta parte podemos hacer una analogía con una persona que no ve (invidente): entonces ¿cómo distingue él un camino que nunca transitó?, habrá huecos, desniveles y demás obstáculos, ¿cómo sabe si en una pared hay una ventana o una puerta?, etc. El invidente interactúa con ayuda del oído y el tacto usando un bastón para escanear las superficies y sus características. De forma similar, si queremos investigar o averiguar cómo es un nanomaterial, hacemos incidir electrones y tenemos que identificar si son los mismos electrones incidentes o son electrones de la muestra. La dificultad está en ¿cómo distinguir unos de otros?; si se desvían los electrones incidentes 
Figura 3. Principales señales debido a la interacción del haz de electrones con la muestra.

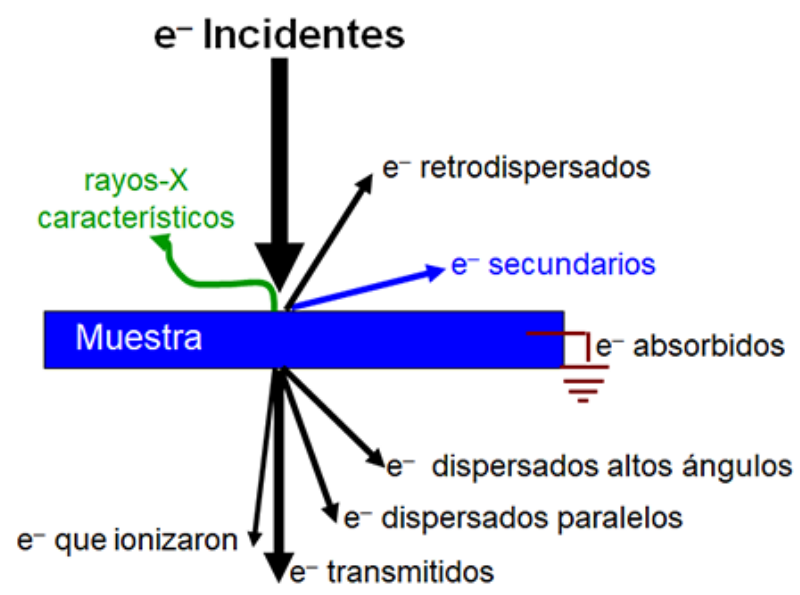

Nota: Color negro: electrones provenientes del cañón. Color azul: electrones de la muestra. Color verde: onda electromagnética generada por la transición de electrones.

Fuente: Elaboración del autor.

¿en qué ángulo lo hacen?, etc. Entonces un electrón que incide sobre la muestra tiene varias posibilidades (figura 3) estos pueden: atravesar sin desviarse, ionizar al átomo de la muestra, desviarse en un ángulo o interaccionar con el núcleo de los átomos que conforman la muestra. Las preguntas a responder son: ¿cuál de todos estos fenómenos ocurrió?, ¿hay forma de distinguir uno de otro? La respuesta a ambas preguntas es: sí, podemos distinguir lo que pasó de forma clara. ¿Cómo se hace?, para ello se ponen los detectores adecuados en las posiciones convenientes (estratégicas) y el detector nos dirá si llegaron electrones o no. ¿Cómo sabremos en dónde poner los detectores?, para responder a esta pregunta tendremos que estudiar la dispersión de electrones por átomos fijos en una muestra, existe una basta y amplia literatura en esta área (David y Barry, 2009). Ahora bien, tomando en cuenta el análisis previo, podemos imaginarnos que los detectores tienen que estar cerca de la muestra a una distancia adecuada. Para entender con más detalle las interacciones de los electrones incidentes, los separaremos en dos grupos: electrones que ionizan a los átomos de la muestra y los electrones que se dispersan debido a la interacción con la muestra. (Para entender estos fenómenos se usa el modelo atómico de Rutherford).

Una parte de los electrones incidentes ioniza los átomos de la muestra Para que un electrón llegue a la muestra se debe acelerar y, por consiguiente, lleva energía suficiente para ionizar. Entonces, cuando un electrón ioniza al átomo de la muestra, tenemos dos opciones para conocer acerca de la mues- 
tra en estudio: determinando la energía que perdió el electrón incidente al ionizar es responder ¿qué pasa con el átomo ionizado?

En la primera opción, el electrón sigue su viaje hasta llegar a un medidor de energía (filtro de energía) para determinar cuanta energía perdió en el proceso de la ionización (figura 3 , electrones que ionizaron). Por este método conocemos la energía con la que estuvo ligada el electrón al átomo de la muestra y así determinaremos el elemento químico que conforma la muestra. Además, con este proceso de medir la energía perdida en la ionización, es posible determinar la energía de enlace o el estado de oxidación de los átomos que conforman la muestra. Resultando un método adecuado para caracterizar los nanomateriales.

En la segunda opción, el átomo se queda sin un electrón en alguna capa electrónica. Por ejemplo, cuando el átomo queda ionizado en la capa K. Entonces, al caer un electrón del nivel energético superior ( $\mathrm{L}, \mathrm{M}, \mathrm{N})$ emite rayos$\mathrm{X}$ característicos (figura 3): la energía de estos rayos-X son la huella digital del átomo donde se originan las transiciones del electrón. Por consiguiente, al medir la energía de estos rayos-X característicos, nos revela la composición elemental de la zona donde incidió el haz de electrones. Por esta técnica se determinan las zonas en la que está un tipo de átomo que conforma la muestra. Y un material en estudio (muestra) puede contener varios átomos; luego, con el proceso de medir la energía de los rayos-X característicos, sabremos en qué posiciones de la muestra está un determinado tipo de átomo.

\section{Otra buena parte de los electrones incidentes en la muestra se dispersan}

Esta desviación de electrones incidentes por la muestra puede ser: paralela o en distintas direcciones arbitrarias.

En el primer caso, la desviación paralela a diferentes ángulos se genera por un efecto similar al que generaría una superficie conformada por espejos. ¿Hay “espejos” para los electrones incidentes en la muestra? la respuesta es sí, los átomos que conforman un material (muestra) en su gran mayoría están perfectamente ordenados. Es decir, están formados o alineados como los militares en un desfile cívico, tan perfectamente alineados al punto de generar la ilusión de ver como un único soldado a toda una fila o columna de soldados formados. A este proceso en los materiales se le denomina cristalización. En un cristal, los átomos están enlazados formando figuras geométricas perfectas. Este tipo de materiales cristalinos desvían a los electrones incidentes de forma paralela a distintos ángulos determinados (figura 3). A este último fenómeno se le llama difracción de electrones; y es provocado por la existencia de planos cristalinos en las muestras cristalinas "espejos". Estos electrones nos dan información acerca del tipo de cristales. Por consiguiente, podemos determinar las distintas formas cristalinas de los nanomateriales con este tipo de señal. A la imagen obtenida con estos electrones se le llama patrón de difracción de electrones. 
En el segundo caso, la desviación de los electrones es en distintas direcciones arbitrarias, es decir, no es procedente de planos cristalinos. Entonces, ¿quién provoca esta forma de desviación?, la respuesta es: un material no necesariamente está conformado por un mismo tipo de átomos, cada átomo puede ser de distinto tamaño (átomos ligeros y pesados). Por ejemplo, los óxidos están conformados por un enlace entre un metal y un oxígeno, también algunas aleaciones de materiales (muestras) contienen átomos pesados y ligeros. Al interaccionar con el núcleo de estos átomos, los electrones incidentes desvían a los electrones en diferentes ángulos, algunos inclusive se regresan (figura 3, electrones retrodispersados y dispersados altos ángulos — como en el caso del experimento de Rutherford) (video YouTube consultado, 2020) ${ }^{3}$ - . Al detectar estos electrones desviados sabemos del tipo de núcleos que tienen los átomos que conforman la muestra en estudio, debido a que los átomos pesados tienen núcleos más grandes y desvían mayor cantidad de electrones incidentes. Por consiguiente, con este tipo de imágenes obtenemos la composición de las muestras, es decir, podemos distinguir átomos ligeros y pesados. La detección de estos electrones desviados en diferentes direcciones nos da información de los materiales en donde los átomos están desordenados (materiales no cristalinos). Los nanomateriales no necesariamente están ordenados, también pueden estar conformados por diferentes tipos de átomos. Los electrones desviados por el núcleo de los átomos se registran con el detector llamado high angle annular dark field (HAADF) y a la imagen obtenida con estos electrones se le llama contraste-Z, esta imagen lleva información acerca del tipo de núcleo atómico que conforman las muestras.

Estos fenómenos explicados en la interacción de electrones incidentes y las muestras en estudio se deben tener presentes, para la interpretación de las distintas imágenes que se obtienen con los microscopios electrónicos.

\section{Ejemplos en el estudio de nanomateriales}

A continuación, mostraré ejemplos del estudio de materiales por microscopía electrónica. En cada caso se explicará la interpretación correspondiente, basada en los fenómenos que se describieron en la sección anterior. Primero, presentaré un estudio sistemático detallado de dos nanopartículas mostrando la diferencia entre ellas, luego se incorporarán otros ejemplos. Para cada caso se explicarán en detalle las imágenes obtenidas debido a la interacción del haz de electrones con la muestra.

Se requiere estudiar dos muestras en forma de partículas (polvo) de diferente color (figura 4a). Responderemos tres preguntas iniciales: ¿cómo es la forma de cada una de las partículas?, ¿a qué se debe la diferencia de color?, y, ¿qué tamaño tendrán las partículas? A simple vista solo se alcanzan a distinguir los colores, mas no podemos saber el tamaño ni qué partículas con-

\footnotetext{
${ }^{3}$ https://youtu.be/knlrOsqHzLU
} 
forman la muestra. Quizás pueden tener tintes, veamos cómo se verían si las dispersamos en agua tri-destilada. Ambas muestras se dispersan en viales separados (figura 4b): en cada una se puso la cantidad mínima señalada con flechas en la figura 4a. En la dispersión, hay una diferencia en la tonalidad, una es blanca (A) y la otra es más o menos color rojizo (B) y esta última, ahora se parece a la muestra A de la figura 4a en color. Al dispersar las partículas en agua, no podemos distinguirlas entre ellas. En el afán de responder a nuestras tres preguntas iniciales, podemos poner una gota de cada dispersión en el portamuestras para el MET (figura 4c): la dejamos secar para que se evapore el agua y solo queden las partículas de interés —en la gota deben ir algunas partículas por lo menos-. Ahora bien, la pregunta es ¿podremos ver las partículas en el microscopio electrónico?, ¿será suficiente la cantidad de muestra? En la figura 4c, se observa el tipo de rejilla que usamos, vemos la membrana señalada con flechas azules, las partículas quedan ancladas sobre ésta para ser estudiadas por MET. Este procedimiento que se describió es la forma de preparar muestras en forma de polvo para MET.

Ya que ambas muestras quedaron preparadas para el estudio por MET, iniciaremos el procedimiento para responder una de nuestras tres preguntas iniciales: ¿podremos distinguir las partículas que dan color a cada vial de la figura 3b? Para esto, usaremos un microscopio electrónico de transmisión marca Hitachi modelo HT7700, año de fabricación 2015 (Espinosa Magaña, 2016). Las imágenes se adquieren en el modo de transmisión (figura 5): es decir, formamos las imágenes con los electrones que no se han desviado. Estas imágenes nos muestran unas partículas del orden de $20 \mathrm{~nm}$ señaladas con flechas (color guinda): también vemos aglomeraciones de estas partículas con tamaños del orden de $250 \mathrm{~nm}$. Vemos que ambas imágenes son casi iguales salvo algunos puntos oscuros en la imagen de la figura $5 \mathrm{~b}$ señalados con flechas (color blanco) que casi no se distinguen. Por consiguiente, con estas imágenes obtenidas en esta modalidad aun no es posible distinguir categóricamente

Figura 4. Partículas con distinto color, imágenes obtenidas con cámara de celular. a) Partículas, y, b) viales con dispersión de las partículas en agua tri-destilada. c) Portamuestra de Cu para TEM con membrana de carbón con huecos, donde quedan anclada las partículas.
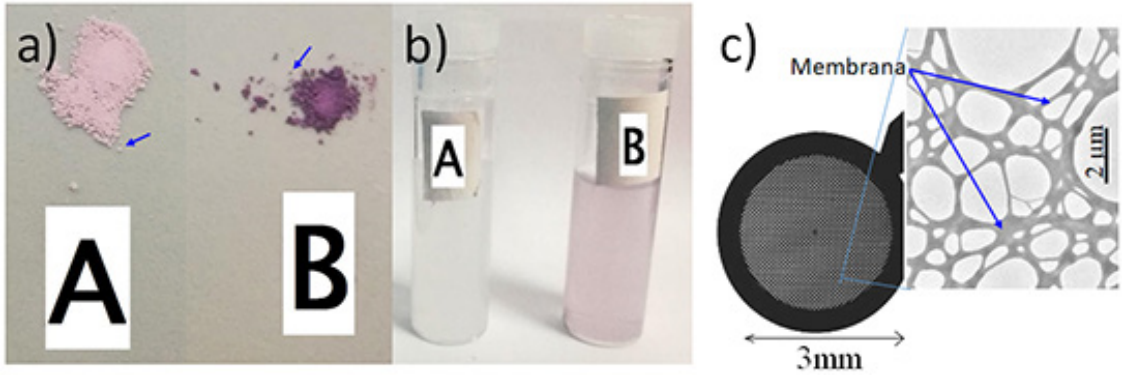

Fuente: Elaboración del autor, imágenes obtenidas en laboratorio CIMAV. 
Figura 5. Imágenes con electrones transmitidos: a) muestra A, y, b) muestra B.
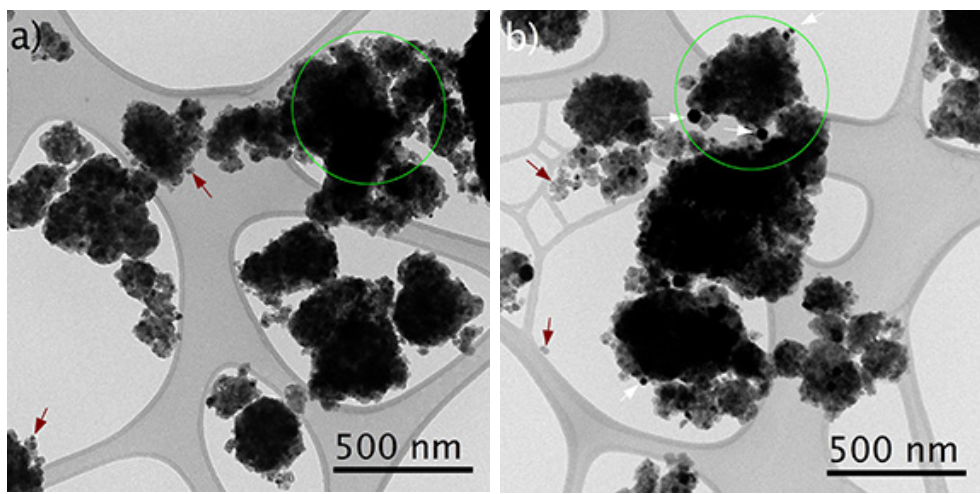

Fuente: Elaboración del autor, imágenes obtenidas en laboratorio CIMAV.

entre ambas partículas. A pesar de que estas imágenes tienen una magnificación de 30 mil veces, no es posible diferenciarlas al usar electrones transmitidos. Como aún no se distingue claramente entre las dos muestras, recurriremos a otro tipo de interacción de electrones con la muestra, en busca de poder identificar mejor la diferencia entre ambas.

Revisando las capacidades del microscopio en uso encontramos que el equipo tiene para medir los rayos-X característicos (detector EDS). Esta señal es generada por cada átomo ionizado, al pasar un electrón de niveles energéticos superiores a inferiores. Entonces, con la ayuda del detector EDS mediremos la energía de los rayos- $\mathrm{X}$ característicos, para ver si hay átomos diferentes entre las muestras A y B. Para este propósito se iluminan con los electrones incidentes en las zonas marcadas con círculo de color verde (figura 5): luego, al activar el detector EDS, se obtienen los espectros de la figura 6; en el espectro para la muestra A (figura 6a) vemos las intensidades correspondientes al $\mathrm{C}, \mathrm{Ti}, \mathrm{O}$ y $\mathrm{Cu}$; los del $\mathrm{C}$ y $\mathrm{Cu}$ pertenecen a la rejilla que se usó para soportar las partículas (figura 4c). Entonces, a la muestra A le pertenecen solo Ti y O, podría ser que este material sea óxido de titanio. En el caso del espectro de la muestra $B$, encontramos las intensidades que corresponden al $C$, $\mathrm{Ti}, \mathrm{O}, \mathrm{Cu}$ y $\mathrm{Au}$, igual que en la otra muestra las intensidades del $\mathrm{C}$ y $\mathrm{Cu}$ corresponden a la rejilla, pero el Au sí es de la muestra. En conclusión, encontramos que en la muestra B hay Ti, O y Au. Ahora la pregunta es ¿cómo estará el Au en la muestra B?, ¿distribuido uniformemente, aglomerado como partículas, o solamente estará en algunas zonas localizadas?, etc. Lo importante es que se encontró una primera diferencia entre las muestras A y $\mathrm{B}$.

Para identificar las zonas donde está cada elemento químico detectado, se hará una mapeo elemental. Para lo cual debemos hacer un mapeo (imagen) en el modo STEM (con iluminación cónica en modo escaneo): esta es otra técnica del microscopio para construir imágenes con el detector EDS. Para 
Mundo Nano | ARTículos DE REVISıón | www.mundonano.unam.mx

13(25), 101-131, julio-diciembre 2020 | https://doi.org/10.22201/ceiich.24485691e.2020.25.69626

Francisco Paraguay-Delgado

Figura 6. Espectros del contenido elemental con detector EDS de las muestras a) A, y, b) B.
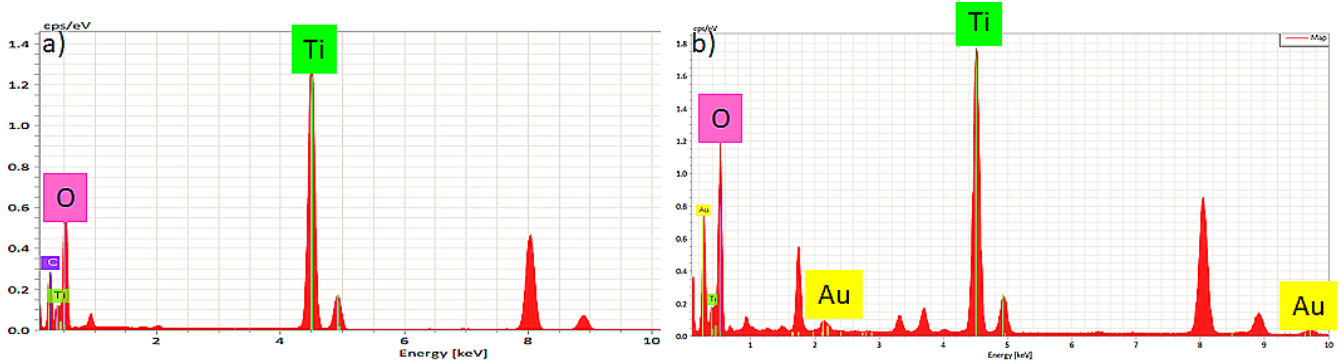

Fuente: Elaboración del autor, imágenes obtenidas en laboratorio CIMAV.

ello, se sincroniza la zona de incidencia del haz de electrones convergente y el detector EDS. Al estar sincronizada la posición de incidencia del electrón sobre la muestra y la detección de rayos-X característicos, se construyen imágenes con estas señales, a esto se le denomina mapeo elemental.

Las imágenes de las figuras 7 y 8 pertenecen a los mapeos elementales correspondientes a las muestras A y B, respectivamente. En el caso de las imágenes de la muestra A (figura 7): la imagen de la muestra se correlaciona con las imágenes formadas para los elementos Ti y O, es decir, están en las mismas posiciones. También vemos la membrana de carbón que corresponde al soporte de la rejilla, en consecuencia, podríamos decir que Ti y $\mathrm{O}$ están enlazados químicamente formando un compuesto.

En el caso de la muestra B (figura 8) la imagen también se correlaciona con las formadas para los elementos Ti y O; sin embargo, los puntos más oscuros de la imagen se correlacionan en ubicación con la imagen para el Au.

Figura 7. Mapeo elemental de la muestra A. a) Imagen en modo STEM, campo claro de la zona de análisis elemental, imágenes donde están los elementos químicos; b) C; c) Ti, y, d) 0.

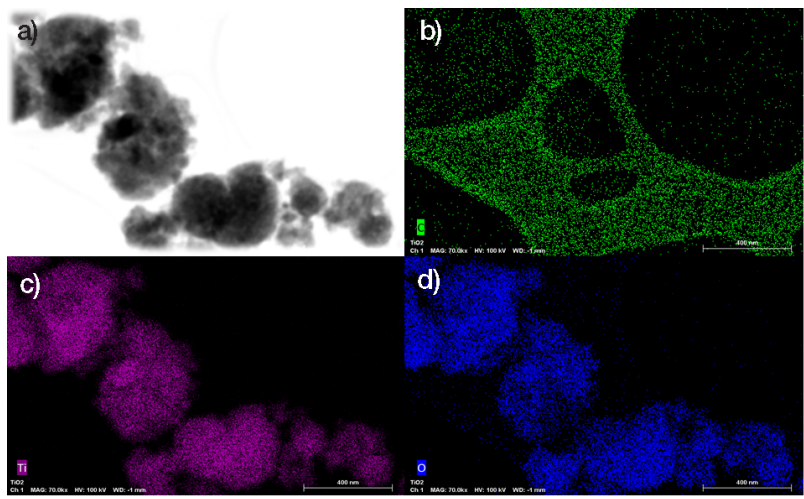

Fuente: Elaboración del autor, imágenes obtenidas en laboratorio CIMAV. 
Así, en ambas muestras están los mismos átomos, pero en el caso del oro están en algunas zonas localizadas, lo cual nos permite intuir o proponer que Ti y O están enlazados formando óxido de titanio $\left(\mathrm{TiO}_{2}\right)$ y el Au está disperso como metal. El Au está formando partículas metálicas nanométricas, esto lo sabemos debido a que los diámetros son menores a $100 \mathrm{~nm}$. En conclusión, haciendo uso de la detección de rayos-X característicos espectralmente y también haciendo mapeos, encontramos la diferencia entre las dos muestras A y B. En la muestra B, las NPs de Au están dispersas en un soporte de $\mathrm{TiO}_{2}$, esta es la razón por la que las partículas difieren en color.

Hasta ahora se identificó la morfología, composición química y la distribución elemental de ambas muestras. Para hacer un estudio completo de los materiales en estudio, también se debe identificar si son cristalinas o no. Por eso es indispensable detectar si hay electrones dispersados paralelamente (electrones difractados). Para ello se seleccionan zonas circulares con diámetro $\sim 500 \mathrm{~nm}$ (círculo color verde en la figura 5) y se cambia el microscopio al modo de difracción para ver los patrones respectivos para cada muestra.

Figura 8. Mapeo elemental de la muestra B. a) Imagen en modo STEM, imagen campo claro de la zona de análisis, imágenes donde están los elementos químicos; b) Ti; c) 0, y, d) Au.

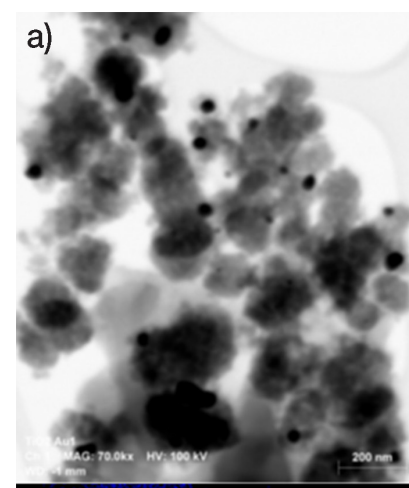

c)

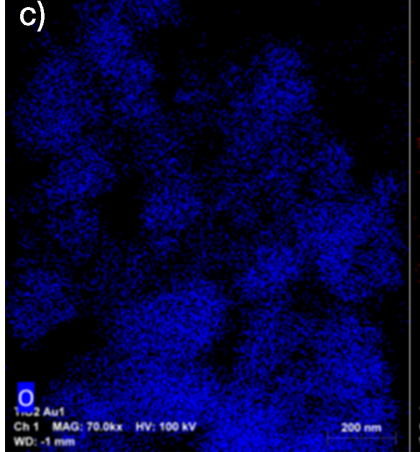

Fuente: Elaboración del autor, imágenes obtenidas en laboratorio CIMAV.

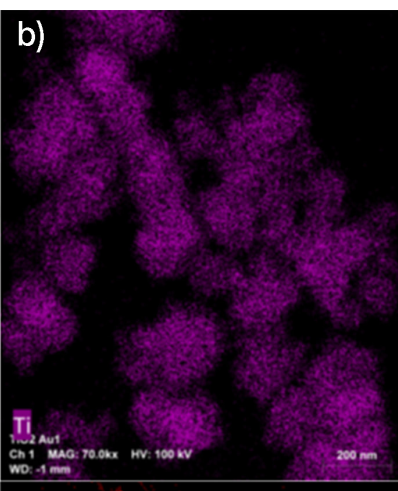

d)
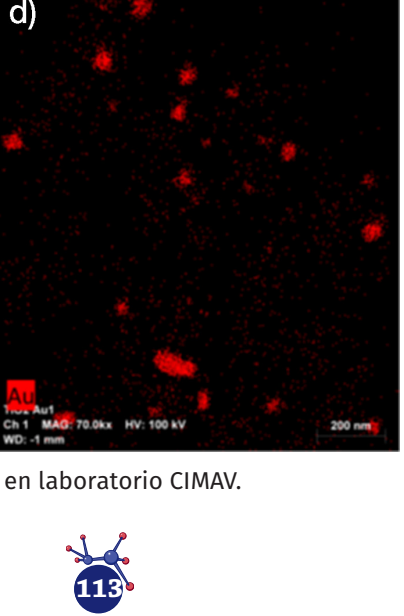
La figura 9 muestra los patrones de difracción de electrones desde las zonas seleccionadas para las muestras A y B, respectivamente. Estas imágenes nos muestran líneas circulares, con distintos tamaños de radio. Cada círculo pertenece a una familia de planos cristalinos, de tal modo que estos círculos provienen de varias distancias interplanares. Estos patrones de difracción son circulares debido a la superposición de electrones difractados provenientes de muchos cristales. En la figura 5, vemos una gran aglomeración de cristalitos, cada uno con tamaños del orden de $20 \mathrm{~nm}$, esto significa que los electrones interactúan con todos estos cristales, por eso se ven círculos concéntricos en el patrón de difracción procedente de un conjunto de cristales. Estos patrones de difracción son similares para ambas muestras y según la indexación el material es $\mathrm{TiO}_{2}$ fase anatasa, porque las distancias interplanares coinciden para este material. En la figura 9 se ponen los índices de Miller (notación - 3 números entre paréntesis) para cada círculo. No vemos diferencia en esta modalidad, ni tampoco se distinguen los haces difractados de las partículas de oro en la muestra B. Esto es porque la gran mayoría de los cristales son de $\mathrm{TiO}_{2}$, concluyendo que ambas muestras son policristalinas.

Hasta este momento sabemos que la muestra B tiene dispersas partículas nanométricas de oro. Las siguientes preguntas a responder serían en cuanto al $\mathrm{TiO}_{2}$ y al Au ¿qué forma tendrán cada tipo de partícula?, ¿serán cristalinas cada una de ellas?, ¿se podrán ver distancias interplanares?, y, ¿se podrán ver columnas atómicas? Para responder estas preguntas necesitamos usar otro microscopio electrónico con mayor capacidad en resolución, con una fuente de electrones que provea mayor cantidad de electrones (emisión de campo): con corrector de aberración esférica en modo de escaneo (STEM) y con detectores más precisos y eficientes.

Uno de los equipos que cumple con estos requerimientos es el microscopio JEM2200FS (tabla 1) del Laboratorio Nacional de NanotecnologíaCIMAV (Espinosa Magaña, 2016). Por consiguiente, estudiaremos las mismas

Figura 9. Patrones de difracción de electrones de las muestras a) A, y, b) B.
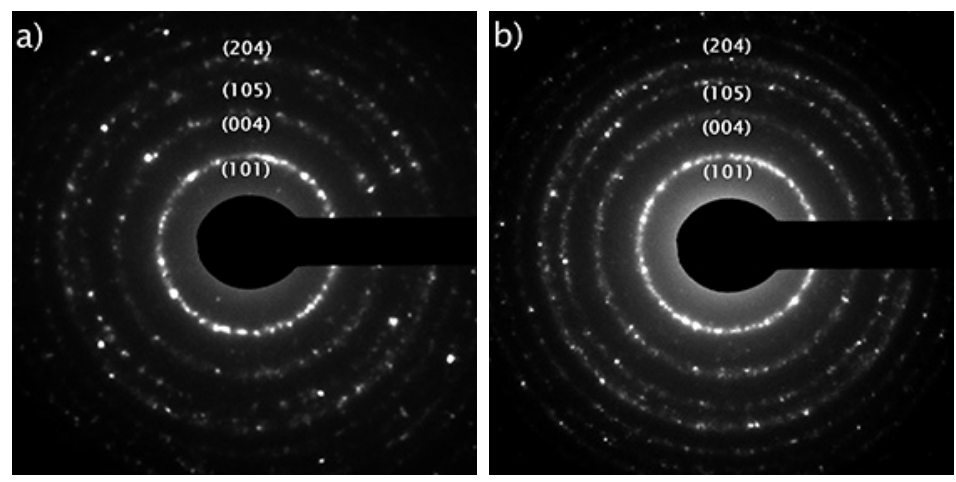

Fuente: Elaboración del autor, imágenes obtenidas en laboratorio CIMAV. 
muestras con el microscopio JEM2200FS. En este equipo, usaremos el modo STEM para obtener imágenes con los detectores de electrones transmitidos (campo claro) y detector de electrones dispersados por el núcleo de los átomos (HAADF) para obtener imágenes en contraste- $Z$.

La figura 10 muestra dos imágenes de la misma zona en modo STEM de la muestra A, ambas obtenidas con distintos detectores. La imagen en la figura 10a fue obtenida con el detector de campo claro (electrones transmitidos) donde podemos distinguir de forma más clara el aglomerado de partículas con distintos tamaños. En las zonas marcadas con flechas vemos las famosas bandas de Moire (líneas claras y oscuras): éstas se forman debido a la interferencia generada por dos cristales de la misma distancia interplanar o similares, pero ligeramente rotadas o desplazadas entre ellas. Las partículas de $\mathrm{TiO}_{2}$ son del orden de $20 \mathrm{~nm}$ y parecen ser láminas casi circulares. Sin embargo, en la figura $10 \mathrm{~b}$ se muestra la imagen obtenida de la misma zona con el detector HAADF (electrones dispersados por el núcleo de los átomos): en esta podemos observar que las partículas no son laminares, más bien, tienen un determinado volumen. La obtención de esta imagen se basa en la cantidad de interacciones de los electrones incidentes con el núcleo de los átomos de la muestra. Entre más gruesa es la zona estudiada, hay mayor interacción y, por consiguiente, esa zona se ve más brillante (intensa). Por lo tanto, ambas imágenes son complementarias para obtener información morfológica de la muestra.

Continuando con el estudio de las dos muestras A y B, las imágenes mostradas en la figura 11 pertenecen a la muestra $B$, que, como sabemos, contiene NPs de Au. La imagen de la figura 11a fue obtenida con el detector de campo claro donde las zonas de las partículas de Au se ven más oscuras, esto es debido a que el metal Au tiene un número atómico más alto (átomo pesado). Esta característica impide el paso de muchos electrones, porque los

Figura 10. Imágenes de la misma zona en el modo STEM de la muestra A. Se obtuvieron con: a) electrones transmitidos (campo claro): y, b) electrones dispersados altos ángulos (contraste- $\mathrm{Z}$ ).
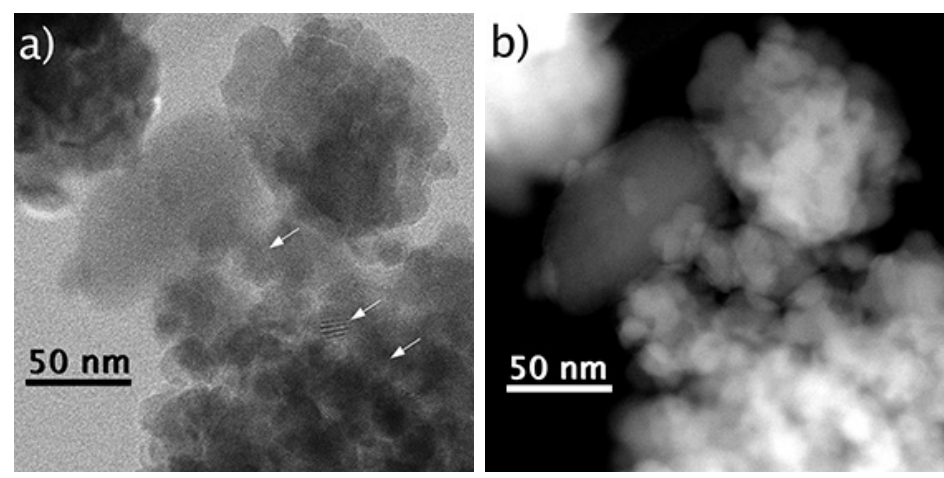

Fuente: Elaboración del autor, imágenes obtenidas en laboratorio CIMAV. 
dispersa con el núcleo, razón por la cual se ve más oscuro, pues transmite pocos electrones. Ahora veamos la imagen obtenida con electrones dispersados en distintas direcciones por el núcleo (contraste-Z, figura 11b). En esta imagen, las NPs de Au se ven brillantes (intensas) debido a su núcleo atómico y dispersan más a los electrones, por eso llegan más electrones. Estas partículas tienen formas geométricas triangulares, en general poliédricas, se ve claramente la forma y las caras de cada NP. La partícula más grande no se define con claridad debido a que no está a la misma altura o nivel de las otras partículas claras. En la imagen de la figura 8a, las partículas de Au se veían de forma circular debido al modo de trabajo y a la resolución del microscopio usado, ahora pudimos distinguir su forma.

Con detectores apropiados y con el microscopio electrónico adecuado, es posible distinguir muy bien la forma de las NPs. La calidad con la que se obtienen las imágenes depende mucho de la cantidad de electrones incidentes, es decir, a mayor cantidad de electrones se genera mayor cantidad de interacciones y más señal para los detectores.

Para responder la pregunta ¿cómo son los planos cristalinos? debemos magnificar la imagen mucho más y así poder ver las distancias interplanares. En las imágenes siguientes se ven las distancias interplanares obtenidas de la misma zona con los dos tipos de detectores (campo claro y contraste-Z). Las imágenes de las figuras 12 a y 12 b son de la zona del $\mathrm{TiO}_{2}$, donde vemos líneas hacia diferentes direcciones en ambas imágenes. La primera imagen (figura 12a) fue adquirida con el detector de campo claro, estas líneas se generaron debido a la interferencia de electrones transmitidos y difractados (ondas transmitidas y difractadas - por dualidad onda partícula). La segunda imagen (figura 12b) fue formada por la dispersión de electrones con los núcleos, a esta imagen se le denomina la verdadera imagen de alta resolución. En el caso de las imágenes mostradas en las figuras 12c y 12d, estas

Figura 11. Imágenes de la misma zona, en el modo STEM de la muestra B con detectores: a) campo claro, y, b) contraste-z.

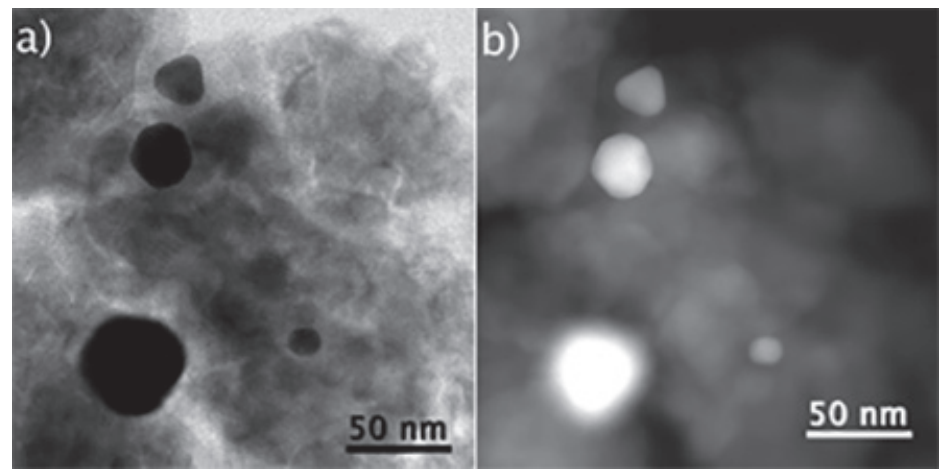

Fuente: Elaboración del autor, imágenes obtenidas en laboratorio CIMAV. 
Figura 12. Imágenes que muestran distancias interplanares, para $\mathrm{TiO}_{2}$ : a) campo claro, y, b) contrasteZ. Para una partícula de oro: c) campo claro, y, d) contraste-Z.

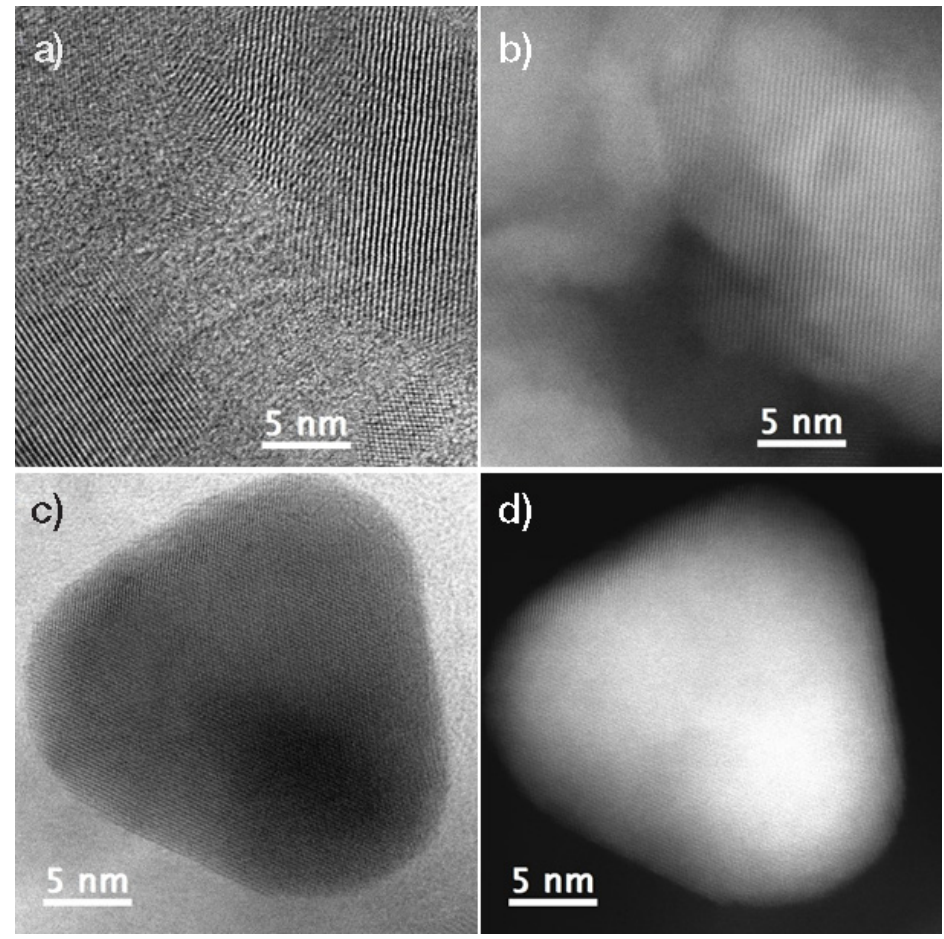

Fuente: Elaboración del autor, imágenes obtenidas en laboratorio CIMAV.

proceden de una de las partículas triangulares de oro, aquí también se ven las distancias interplanares aún más cercanas.

Para obtener estas imágenes con mayor magnificación, se irradia con gran cantidad de electrones áreas pequeñas de la muestra, en muchos casos se generan daños a la muestra, por la irradiación de electrones energéticos. En conclusión, las partículas tanto del $\mathrm{TiO}_{2}$ como Au son cristalinas, por eso se ven los planos cristalinos en las imágenes correspondientes.

Si queremos conocer aún más acerca de la estructura cristalina de las muestras, es necesario conocer sus parámetros cristalinos. Las preguntas a responder serían ¿cómo serán las celdas unitarias en cada tipo de material?, ¿qué simetrías tendrán estos materiales en estudio?, ¿cómo están apilados los átomos en las NPs? En muchos tipos de NPs interesa saber cuáles son los parámetros cristalinos, para tal propósito es necesario hacer difracción de electrones a cada una de las NPs. Esto quiere decir que se deben obtener los patrones de difracción de electrones de cada NP (véase la figura 3). Para ello, es necesario hacer incidir un haz de electrones paralelos solamente en una NP. 
Normalmente los MET vienen configurados para hacer difracción de electrones desde áreas grandes ( $\geq 0.15 \mu \mathrm{m})$. Para estudiar cada NP es necesario tener un haz paralelo con diámetro menor o igual a $30 \mathrm{~nm}$; entonces, cada usuario tiene que reconfigurar el sistema de iluminación del equipo (lentes condensadoras) de acuerdo con su necesidad. En nuestro caso fue necesario reconfigurar la corriente en las lentes del sistema de iluminación del microscopio JEM2200FS en el modo STEM. A este proceso se le conoce como: la configuración del microscopio para un interés específico; esto es como personalizar tu computadora para un uso exclusivo, donde solo instalas el software que más utilizas y los botones del teclado se configuran para un propósito específico. De igual forma, el microscopio electrónico también se personalizará, es decir, no se usa en la configuración comercial del fabricante. En este caso, el microscopio JEM2200FS fue configurado para hacer patrón de difracción en el modo STEM, cuyo haz casi paralelo tiene un diámetro del orden de $15 \mathrm{~nm}$ (Paraguay-Delgado, et al. en preparación). Con esta nueva configuración del equipo se obtuvieron las imágenes de la figura 13 desde la muestra $\mathrm{B}$. La imagen de la parte central se obtuvo con el detector HAADF, imagen en contraste- $Z$ y los patrones de difracción se adquirieron en campo claro (electrones transmitidos en este caso difractados). Se muestran cuatro patrones de difracción correspondientes al oro (figura 13 en su parte superior) y otros cuatro pertenecientes al $\mathrm{TiO}_{2}$ (figura 13 en su parte inferior). En la imagen central (D-STEM Image): se marcan las zonas desde donde se obtuvieron los patrones de difracción que se muestran con los nombres Z1-Au, Z5-Au, Z6-Au y Z8-Au (Z\# significa las distintas zonas de la imagen central y el Au pertenece al oro). Estas son zonas más brillantes y pertenecen a las partículas de oro, podemos distinguir que de una misma partícula de oro provienen diferentes formas de patrón de difracción, esto quiere decir que la partícula puede estar pegada con otro cristal de oro orientado en distinta dirección (imágenes Z5-Au y Z6-Au). También se muestran los patrones de difracción de las partículas del $\mathrm{TiO}_{2}$ con los nombres $\mathrm{Z12}-\mathrm{TiO}_{2}, \mathrm{Z} 15-\mathrm{TiO}_{2}, \mathrm{Z16}$ $\mathrm{TiO}_{2}$ y $\mathrm{Z} 17-\mathrm{TiO}_{2}$. Estos patrones de difracción pertenecen a partículas del $\mathrm{TiO}_{2}$ orientadas en diferentes direcciones, por eso las simetrías en cada uno de los patrones de difracción registrados son diferentes. Dichos patrones de difracción no están indexados, lo cual quiere decir que cada punto brillante se debe identificar con la familia de planos cristalinos en la notación de índices de Miller, este proceso puede ser fácil o tedioso. Los patrones de difracción pueden venir desde una partícula o más de una, es decir, pueden estar superpuestas más de una partícula en la zona de estudio. Lo que se mostró con las imágenes de la figura 13, es la capacidad de configurar un microscopio comercial, para la obtención de resultados muy específicos y de gran utilidad para el estudio de NPs. No obstante, en los ejemplos siguientes de este trabajo se mostrarán los patrones completamente indexados para algunos materiales. 
Figura 13. Patrones de difracción con haz paralelo nanométrico en modo D-STEM, de las partículas de $\mathrm{Au}$ y de $\mathrm{TiO}_{2}$ de forma independiente.

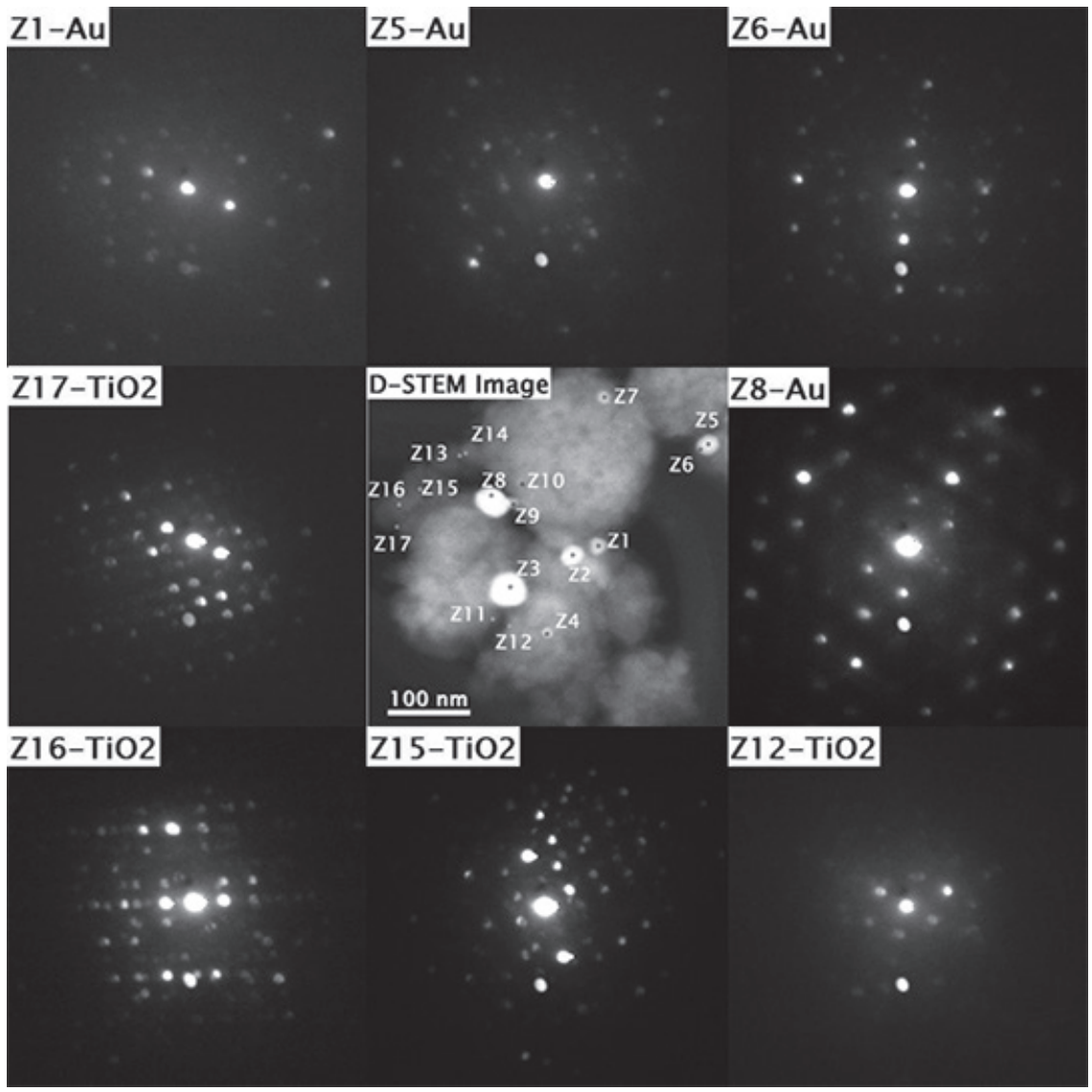

Fuente: Elaboración del autor, imágenes obtenidas en laboratorio CIMAV.

En resumen, este estudio comparativo de las muestras A y B, pudimos distinguir la diferencia entre ellas haciendo uso de las distintas técnicas del MET, usando más de un solo instrumento con diferentes capacidades. Se identificó el contenido de los elementos químicos, donde encontramos que en ambas está presente el $\mathrm{TiO}_{2}$, y en la muestra $\mathrm{B}$ hay NPs de oro con diferentes formas geométricas. También se encontró que las partículas de $\mathrm{TiO}_{2}$ y oro son cristalinas, pues se observaron planos cristalinos los cuales fueron confirmados por los patrones de difracción de área selecta y por difracción con haz paralelo nanométrico de cada partícula, dando mejor calidad de información acerca de la cristalinidad de las partículas en estudio. 


\section{Estudio de otras partículas nanométricas}

\section{Nanopartículas Pt-Ru sobre nanotubos de carbón}

En el área de generación de nuevas fuentes de energía se necesita aleación de NPs para ser usado como electro-catalizador. Por ejemplo, para generar hidrógeno a partir del agua se usan materiales denominados electrocatalíticos. Los mejores catalizadores en este tipo de reacciones químicas están formados por NPs de metales nobles muy costosos como platino, rutenio y paladio. En la imagen de la figura 14, se muestra el estudio de un electro-catalizador, aquí el objetivo fundamental de los investigadores fue sintetizar NPs de Pt-Ru distribuidas sobre nanotubos de carbón, con la composición elemental de igual cantidad - $50 \%$ de cada elemento - en cada partícula. En la imagen de la figura 14a se ve el nanotubo de carbón decorado con nanopartículas, esta imagen se obtuvo con electrones transmitidos. La medición del diámetro de las partículas dio un promedio de $3.7 \pm 0.4 \mathrm{~nm}$, mostrando gran uniformidad. Sin embargo, al hacer el análisis elemental por EDS de tres partículas en modo STEM cuyas posiciones se enumeran en la imagen de la figura 14b, la cuantificación del contenido de los elementos desde los espectros similares a la figura 14c difieren (los resultados se muestra en la tabla adjunta). Los porcentajes atómicos del contenido de Pt y Ru son distintos en cada partícula, de modo que no se cumple con el objetivo fundamental de la síntesis. La tarea es, entonces, encontrar la diferencia y el contenido elemental o compuesto de cada nanopartícula. Para ello, haremos difracción de electrones con un haz nanométrico paralelo a cada partícula.

En la figura 15 se muestra la obtención y su indexación de un patrón de difracción de electrones con haz nanométrico paralelo de una sola partícula. Estas imágenes se obtuvieron en modo de transmisión, con el microscopio electrónico Hitachi modelo HT300 ubicado en National Institute for Nano-

Figura 14. Partículas bi-metálicas sobre nanotubos de carbón multicapa. a) Imagen TEM; b) imagen STEM; c) espectro por EDS y tabla de la composición elemental de tres partículas.
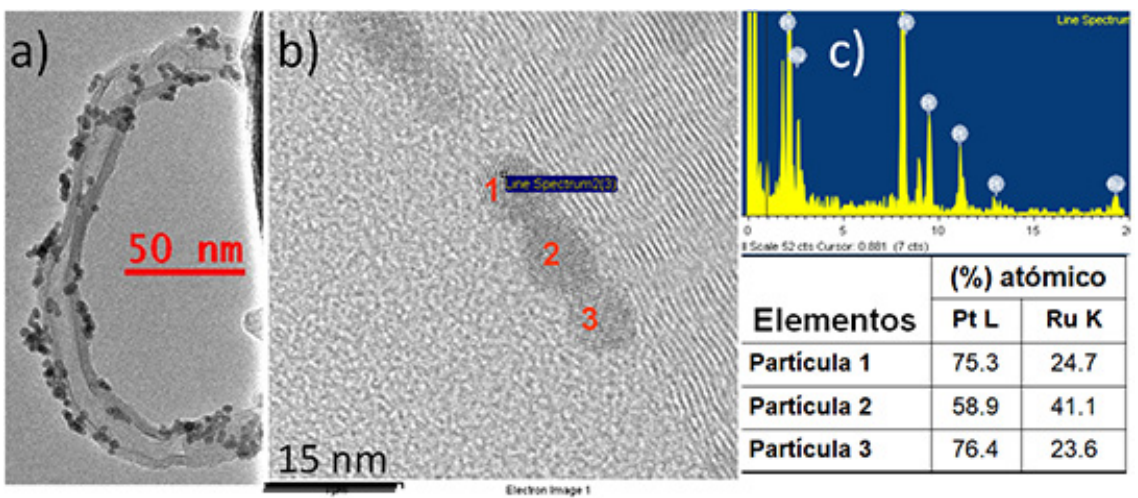

\begin{tabular}{|l|c|c|}
\hline \multirow{2}{*}{ Elementos } & \multicolumn{2}{|c|}{$(\%)$ atómico } \\
\cline { 2 - 3 } & Pt L & Ru K \\
\hline Particula 1 & 75.3 & 24.7 \\
\hline Particula 2 & 58.9 & 41.1 \\
\hline Particula 3 & 76.4 & 23.6 \\
\hline
\end{tabular}

Fuente: Elaboración del autor, imágenes obtenidas en laboratorio CIMAV. 
Figura 15. Difracción de electrones con haz manométrico. a) Partículas sobre nanotubo de carbón; b) zoom de la partícula; c) NBD obtenido, y, d) NBD indexado.

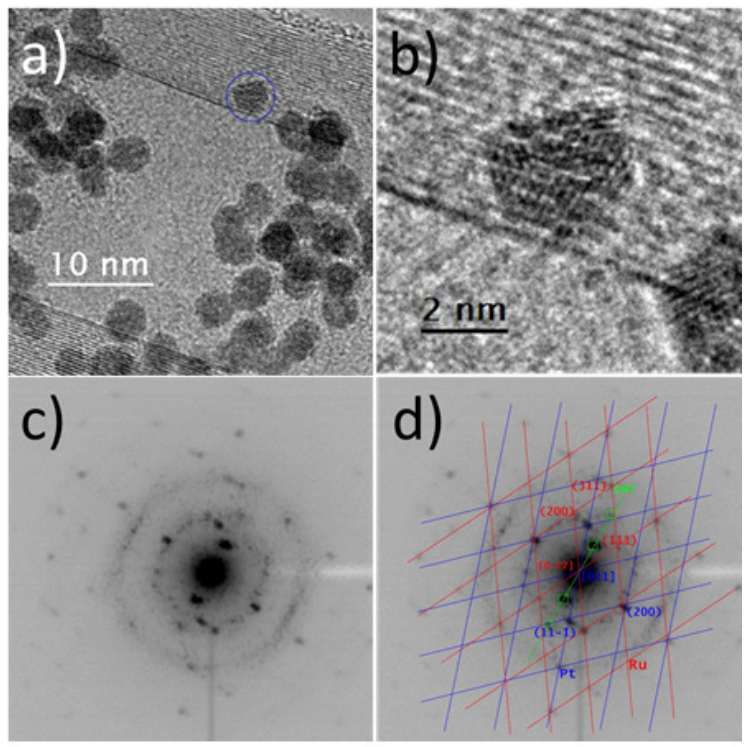

Fuente: Paraguay-Delgado, et al. (2014).

technology (NINT) localizado en la provincia de Alberta, en la ciudad de Edmonton, Canadá. El equipo tiene la opción para hacer patrón de difracción con haz nanométrico paralelo (NBD nanobeam electron diffraction) cuyo diámetro de haz paralelo es del orden de $3.5 \mathrm{~nm}$ (Malac et al., 2008).

La imagen en la figura 15a muestra la distribución de las partículas sobre un nanotubo multipared. En las imágenes vemos distancias interplanares (figura 15b) de los nanotubos y de las partículas, pero midiendo estas distancias no fue posible identificar si es solo $\mathrm{Pt}$, Ru o ambos. Para distinguirlos, se realizó un patrón de difracción con haz nanométrico paralelo a la partícula marcada en círculo azul (figura 15a). La imagen de la figura 15c muestra el patrón de difracción donde los puntos negros son los haces difractados por una familia de planos cristalinos de la partícula, ahora queda la interpretación adecuada de esta imagen. A este proceso se le llama indexación del patrón de difracción. La imagen de la figura 15d muestra la indexación, donde el arreglo de las líneas azules corresponde al Pt y el arreglo con las líneas rojas corresponde al $\mathrm{Ru}$, además, se identifican los haces difractados por el nanotubo de carbón, mostrados sobre la línea verde. La indexación de los haces difractados por la partícula nos dice que está conformada por Pt-Ru. La información mostrada en este trabajo, complementa la información que publicamos en el artículo "Structure and composition of single Pt-Ru electrocatalyst nanoparticles supported on multiwall carbon nanotubes" (Paraguay-Delgado et al., 2014): 
Mundo Nano | ARTículos DE REVISıón | www.mundonano.unam.mx

13(25), 101-131, julio-diciembre 2020 | https://doi.org/10.22201/ceiich.24485691e.2020.25.69626

Francisco Paraguay-Delgado

donde se muestra que otras partículas tienen diferente composición. Siendo esta técnica de la difracción con haz nanométrico paralelo útil para identificar las NPs dispersas en un medio (matriz).

\section{Estudio de nanopartículas de plata}

Las NPs metálicas tienen diversas aplicaciones en nanotecnología. En el caso de la plata, se usa en catálisis, electrónica, óptica, ambiental, antibacterial y biotecnología. Para este tipo de aplicaciones se usan las diferentes propiedades fisicoquímicas. Por ejemplo, la frecuencia de oscilación colectiva de las cargas depende de su morfología, es decir, de la forma y tamaño de las partículas. Con estos valores de frecuencia se mejoran la efectividad en las aplicaciones tecnológicas mencionadas, de allí el interés de sintetizar distintas morfologías. En la figura 16 se muestran algunas morfologías de las NPs de plata, la imagen de la figura 16 a se adquirió por contraste- $Z$ y en ella se aprecian morfologías alargadas denominadas "varillas", todas con el mismo diámetro y casi todos del mismo tamaño. No obstante, las partículas de forma casi esférica tienen un diámetro muy variable, no presentan homogeneidad. La imagen de la figura 16b se adquirió con electrones transmitidos y en la esquina superior izquierda se incluye una imagen a mayor magnificación, ambas imágenes nos muestran varillas mucho más largas con diámetro homogéneo del orden de $50 \mathrm{~nm}$. También vemos partículas con formas poligonales

Figura 16. NPs de plata, diferentes morfologías: a) varillas y esféricas; b) cubos, triángulos y varillas; c) poliedrales; d) láminas.

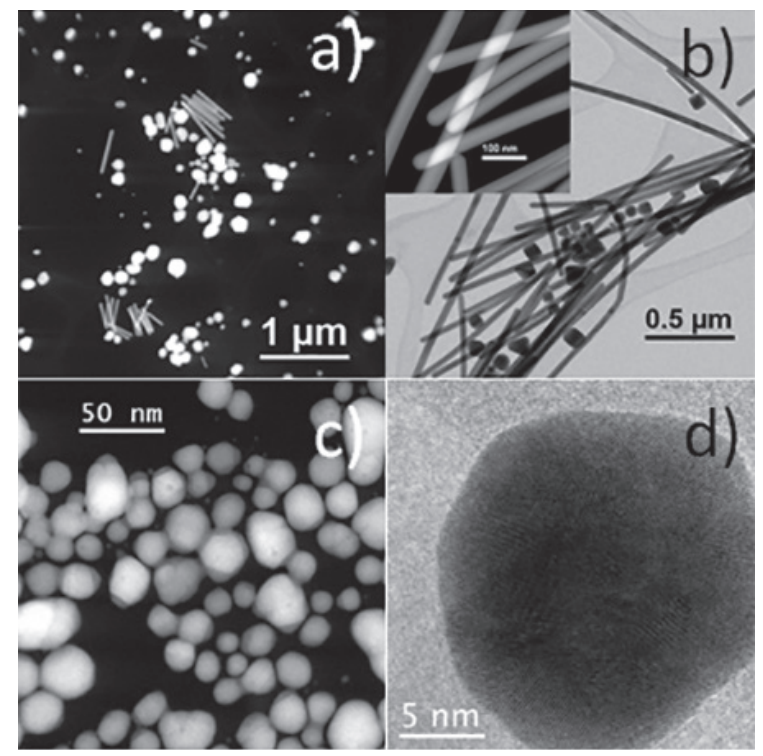

Fuente: Elaboración del autor, imágenes obtenidas en laboratorio CIMAV. 
triangulares y cubos con superficie lisa. El estudio de las propiedades de estos materiales se puede encontrar en una tesis de ingeniería química de la Universidad Autónoma de Chihuahua (Escobedo, 2015). La imagen de la figura $16 \mathrm{c}$ es de contraste-Z, aquí se ven tamaños muy variados de poliedros con superficie lisa cuyos diámetros son menores a $40 \mathrm{~nm}$. En la figura 16d, vemos la imagen de una sola partícula obtenida con electrones transmitidos, la cual tiene un diámetro aproximado de $18 \mathrm{~nm}$, se pueden observar las distancias interplanares pertenecientes al apilamiento de átomos de plata. Reportamos el estudio detallado de los plasmones de estas partículas en función de la irradiación de la luz y morfología en el artículo "Synthesis of silver colloids with a homemade light source” (Sato-Berru et al., 2018).

\section{Quantum dots y su encapsulación en polímeros}

Los quantums dots (QDs) son partículas muy pequeñas en tamaño que se están usando en varias aplicaciones nanotecnológicas. Estas partículas generalmente tienen tamaños menores a $5 \mathrm{~nm}$, la característica principal es que las cargas o los electrones son atrapados en la zona de la partícula y tienen diferentes estados energéticos, con lo cual actúan como átomos gigantescos con niveles de energía cuantizados. Las imágenes de la figura 17 son de QDs de selenuro de cadmio ( $\mathrm{CdSe}$ ): esta imagen se adquirió con el detector de contraste- $Z$, donde se ve una distribución uniforme sin aglomeraciones en cada uno de ellos (figura. 17a) con tamaño promedio del orden de $4 \mathrm{~nm}$. En el caso de la figura 17b, vemos las distancias interplanares, demostrando que cada partícula es cristalina. Reportamos el estudio más detallado de estas partículas en el diseño de un nanosensor de transferencia de energía por resonancia de fluorescencia en el artículo publicado en la revista Science of Advanced Materials (Tirado-Guizar et al., 2014).

Figura 17. QDs de CdSe, imágenes obtenidas en contraste-Z mostrando: a) dispersidad de cada uno, y sus, b) planos cristalinos.
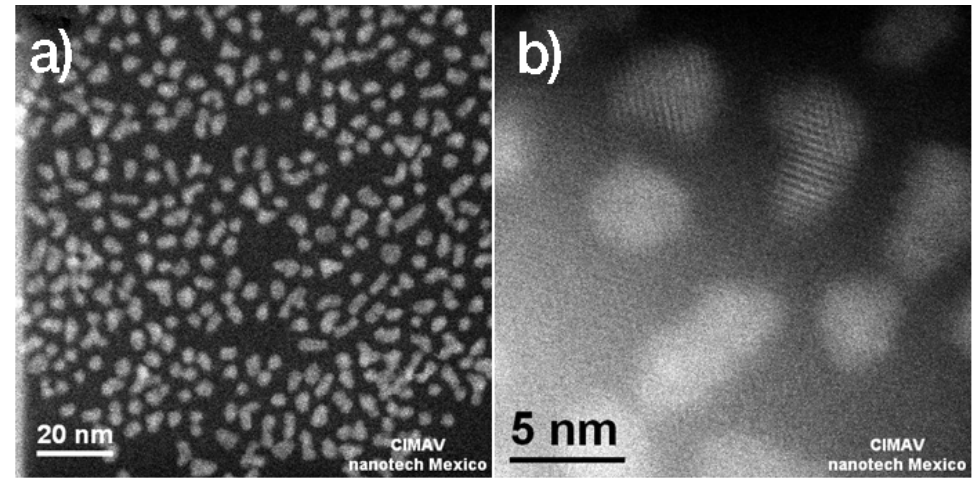

Fuente: Elaboración del autor, imágenes obtenidas en laboratorio CIMAV. 
Una de las aplicaciones más prometedoras de los QDs es su propiedad de fluorescencia. En el caso del CdSe, encapsulando las partículas en polímeros se puede mantener su estabilidad química y sus propiedades de emisión por mucho tiempo. En la imagen de la figura 18a vemos las esferas del polímero polystireno (látex): el propósito fue encapsular las partículas de CdSe en estas esferas, pero no se ve la presencia del QDs en esta imagen obtenida con electrones trasmitidos. Sin embargo, cuando la imagen se adquiere en contraste-Z (figura 18b) vemos los puntos brillantes indicados con flechas de color rojo, los QDs, donde 2 partículas (QDs) están fuera del látex y otras dos sobre el látex. La intención de los investigadores fue encapsular dentro del látex, en este caso no se encapsuló. Para estar encapsulados, los puntos brillantes deberían estar en el centro de cada esfera de látex vista desde cualquier dirección. Esto debido a que en el MET vemos siempre objetos de tres dimensiones proyectados en dos dimensiones. Los QDs se ven brillantes en esta imagen (figura 18b) debido a que el núcleo del átomo de $\mathrm{Cd}$ es grande, razón por la cual dispersa una mayor cantidad de electrones, por ende, registra más electrones el detector de contraste-Z. Estas imágenes son un ejemplo adecuado para entender que los elementos pesados dispersan más los electrones debido al tamaño de su núcleo — por eso el CdSe brilla más-. Nuestros colegas del CIMAV reportaron un estudio del proceso de encapsulación y sus propiedades fluorescentes en el artículo "Effect of synthesis variables on the fluorescence properties of CdSe-polystyrene látexes" (RubioRíos et al., 2012).

Materiales laminares o en dos dimensiones.

En los últimos años han llamado la atención los materiales en dos dimensiones o materiales con crecimiento en capas. Los materiales más populares en esta categoría son los sulfuros de metales: $\mathrm{NbTe}_{2}$ (teleruro de niobio) y grafenos, entre otros.

Figura 18. Quantum dots de CdSe: a) imagen en campo claro, $y, b)$ imagen en contraste-Z.

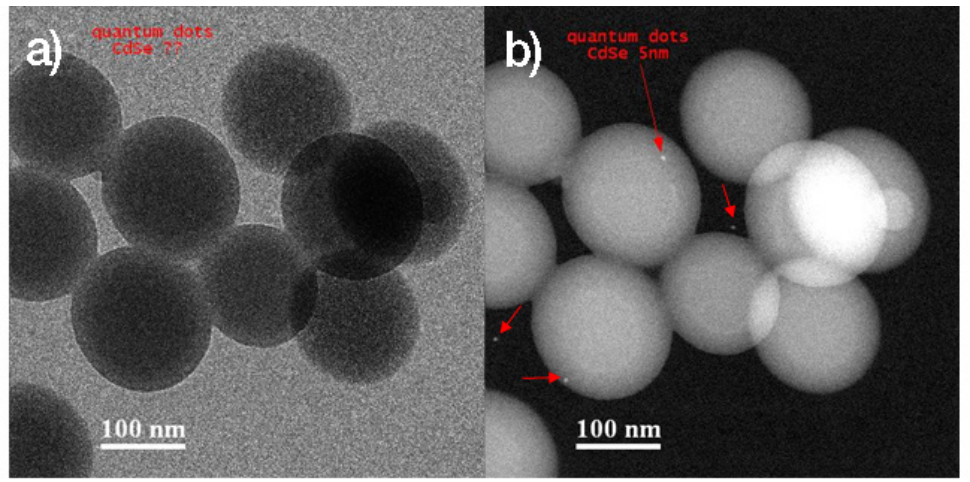

Fuente: Elaboración del autor, imágenes obtenidas en laboratorio CIMAV. 
Hoy en día, el caso del $\mathrm{NbTe}_{2}$ es relevante por su crecimiento en dos dimensiones. En el estudio de este material se adquieren todas las imágenes con electrones transmitidos. En la imagen de la figura 19a vemos la zona de estudio a baja magnificación por MET y en la esquina superior derecha se ve con más claridad. Vemos esta imagen a mayor magnificación en la figura 19b, donde se muestran claramente las distancias interplanares y su transformada de Fourier, ubicada en la esquina superior derecha. En la imagen de la figura 19 c se ve con más claridad la columna de átomos y se puede observar que las líneas más oscuras corresponden a las regiones de Van der Waals que separan las capas Te-Nb-Te. También, la cristalinidad del material fue confirmada con el patrón de difracción de electrones (figura 19d): la variación sistemática de las intensidades en esta imagen nos dice que el material presenta una simetría bien ordenada. En el proceso de indexación, se determinó que la de mayor intensidad corresponde a la familia de planos (20-1) y el otro al (200). Con estos dos planos se determinó el eje de zona del cristal en la orientación [010]. Publicamos un estudio detallado acerca de este material en el artículo "Crystalline structure, electronic and lattice-dynamics properties of $\mathrm{NbTe}_{2}$ " (Barajas-Aguilar et al., 2018).

Figura 19. Imágenes del $\mathrm{NbTe}_{2}$ : a) zona del estudio; b) a mediana magnificación; c) imagen con mayor resolución, se ven las columnas de átomos, y, d) patrón de difracción en el eje de zona [010].

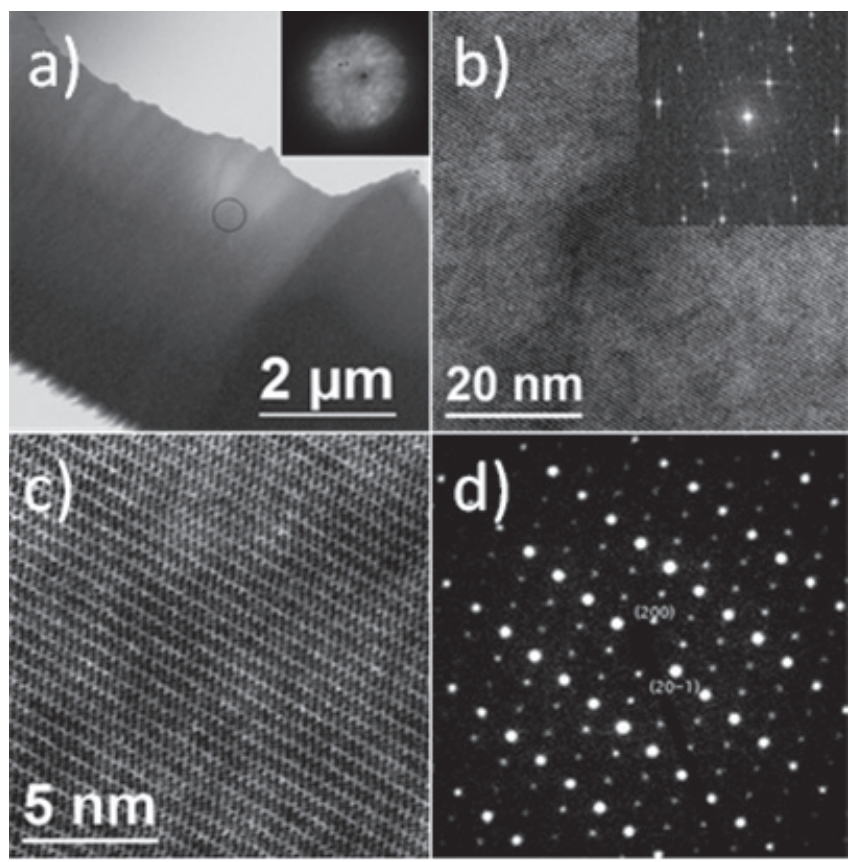

Fuente: Figura 19a) elaboración del autor. Figuras 19b), c) y d): Barajas-Aguilar, et al. (2018). 
La otra familia de materiales en dos dimensiones son los grafenos. Estos materiales son capas de grafito que van desde una sola capa hasta varias, hay muchos reportes y aplicaciones tecnológicas de este material. En la figura 20, vemos la imagen con electrones transmitidos y tres patrones de difracción obtenidos desde las zonas marcadas con círculos de color azul sobre la imagen (figura 20a). El patrón de difracción mostrado en la figura 20b es de la parte más oscura de la imagen zona uno (Z1); en este patrón, vemos que las intensidades presentan una simetría hexagonal, esta simetría nos muestra cómo son los arreglos atómicos en este material. En el grafeno, los átomos de carbono están enlazados formando una simetría hexagonal. Sin embargo, en este mismo patrón se ve un círculo ancho difuso, este tipo de dispersión de electrones es generado por átomos que no forman cristales y se denominan amorfos. Entonces, en esta zona de la imagen más oscura hay material amorfo, razón por la cual se ve más oscura. El patrón de difracción mostrado en la figura 20c se adquirió de la parte más clara de la imagen zona dos (Z2): en este patrón no está la banda ancha, esto quiere decir que no hay material amorfo en las zonas claras del material. Finalmente, el patrón de difracción mostrado en la figura $20 \mathrm{~d}$ es de la zona tres (Z3): donde se muestran las intensidades alargadas intermitentes a lo largo de los círculos concéntricos, pero siguen manteniendo una simetría hexagonal. La forma de las intensi-

Figura 20. Estudio del grafeno, vemos: a) imagen y zonas desde donde se obtienen los patrones de difracción; b) Z1; c) Z2, y, d) Z3.

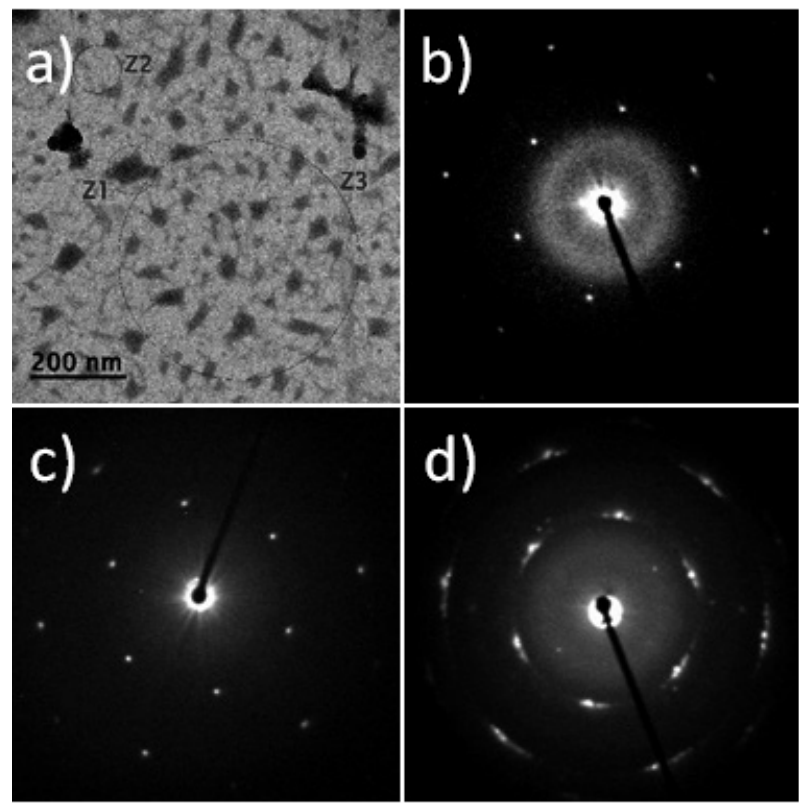

Fuente: Elaboración del autor, imágenes obtenidas en laboratorio CIMAV. 
dades se debe a que provienen de muchos pedacitos de grafeno superpuestos, pero girados ligeramente entre ellos, además, está presente la banda ancha proveniente de las zonas amorfas. En conclusión, este material es una superposición de partículas de grafeno con partículas amorfas. Es decir, una parte del material se está acumulando desordenadamente sin formar material cristalino y se encuentra en las zonas más oscuras de la imagen (figura 20a). Este tipo de partículas se obtienen debido a la secuencia de procesos y/o síntesis usados para obtener el material.

Para la obtención del grafeno se usan diferentes procesos físicoquímicos. Entre estos métodos esta la exfoliación (deshojar) del grafito cristalino con ayuda de procesos químicos o por molienda, etc. (Krishnamoorthy et al., (2013). La figura 21 muestra las imágenes del proceso en la obtención del grafeno, ambas imágenes se tomaron con electrones transmitidos y también se incluye su patrón de difracción respectivo para ambas. En la imagen de la figura 21a vemos zonas uniformes y algunas líneas oscuras; aquí, el patrón de difracción se adquirió desde la zona uniforme, donde sigue presentando una simetría hexagonal, pero con dos intensidades separadas a la misma distancia. Este tipo de intensidades provienen de dos cristales rotados uno con respecto al otro, debido a que en la zona marcada con círculo azul se encuentran dos cristales superpuestos. En el caso de la imagen de la figura $21 \mathrm{~b}$, vemos varias líneas oscuras, las cuales son grafenos enrrollados y superpuestos, su respectivo patrón de difracción muestra dos círculos concéntricos que pertenecen al grafeno. En este caso se ven las intensidades formando dos círculos, debido a que hay haces difractados de grafenos en muchas direcciones.

\section{Óxidos semiconductores}

La síntesis y estudio de las diferentes morfologías de los óxidos semiconductores se han incrementado a la fecha. La aplicación tecnológica de estos ma-

Figura 21. Imagen y patrón de difracción del grafeno por exfoliación, patrón de difracción desde: a) superposición de dos cristales, y, b) superposición de grafenos enrollados.
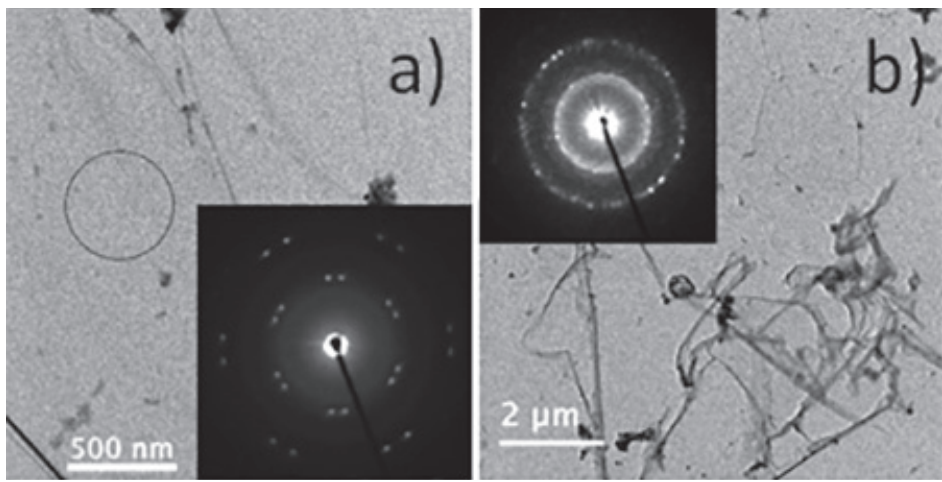

Fuente: Elaboración del autor, imágenes obtenidas en laboratorio CIMAV. 
Mundo Nano | ARTículos DE REVISıón | www.mundonano.unam.mx

13(25), 101-131, julio-diciembre 2020 | https://doi.org/10.22201/ceiich.24485691e.2020.25.69626

Francisco Paraguay-Delgado

teriales depende de la forma, tamaño y composición. Estos óxidos se están aplicando en optoelectrónica, que son dispositivos que convierten señales ópticas en señales eléctricas o viceversa. Entre otros usos, también se utilizan para aplicaciones fotocatalíticas y sensores de gases.

Las imágenes en la figura 22 muestran la morfología del óxido de estaño $\left(\mathrm{SnO}_{2}\right)$ en forma de varillas y en la figura 22d su patrón de difracción de electrones con haz convergente desde una sola varilla mostrada. Las imágenes de las figuras 22 a y $22 \mathrm{~b}$ fueron obtenidas con electrones transmitidos y contraste- $Z$, respectivamente. En la primera imagen se ve el crecimiento desde la parte central siguiendo la dirección radial y en la imagen (figura 22b) en contraste- $Z$ vemos la superficie lisa de cada uno de ellos con terminación piramidal, mostrando claramente las aristas en cada uno de ellos. Las dos imágenes en las figuras 22c y 22e son patrones de difracción con haz convergente, la primera es la parte central y la segunda muestra la simetría del material y las diferentes zonas de HOLZ (high order laue zones) círculos concéntricos intermitentes. Procesando estos patrones de difracción es posible encontrar características de las partículas e información perteneciente de la celda unitaria. La optimización del proceso de síntesis de estas morfologías esta publicado en el artículo "Shape and size contro-

Figura 22. Crecimiento de $\mathrm{SnO}_{2}$ : a) forma de flores; b) detalle da cada varilla; c) patrón de difracción con haz convergente parte central; d) varilla orientada en el eje de zona [200], y, e) difracción de haz convergente mostrando la simetría del cristal de $\mathrm{SnO}_{2}$.

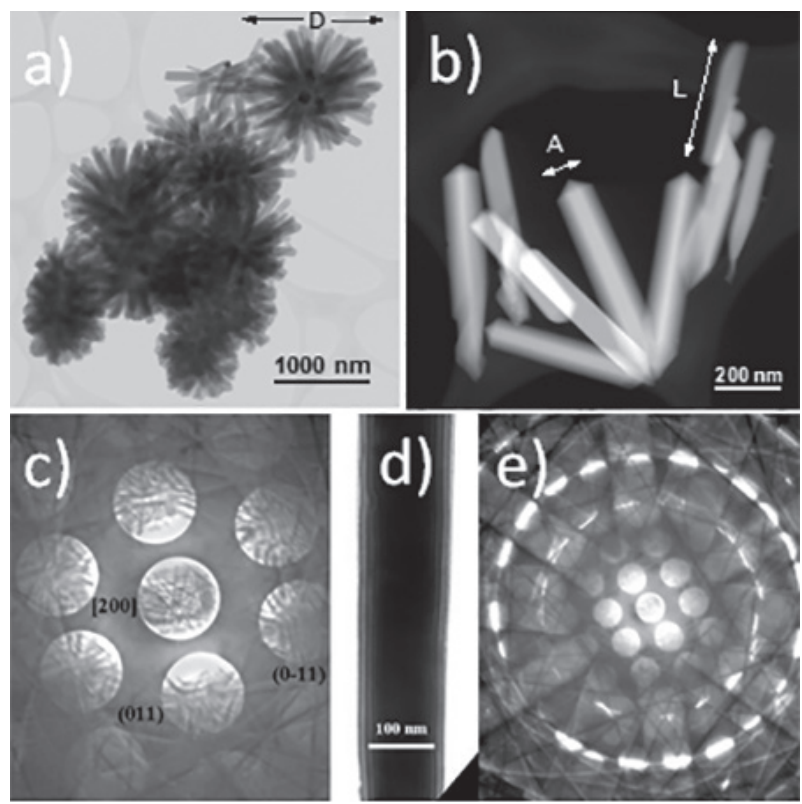

Fuente: a) elaboración del autor, imagen obtenida en laboratorio CIMAV; b)-e), Vásquez et al. (2016). 
lled growth of $\mathrm{SnO}_{2}$ nano-particles by efficient approach" (Vázquez et al., 2016).

Las imágenes de la figura 23 muestran dos morfologías de las partículas de óxido de zinc ( $\mathrm{ZnO})$. Las figuras 23a y 23b son imágenes obtenidas con electrones dispersados por el núcleo (contraste-Z): la primera es de partículas laminares y la segunda de las varillas. Algunas partículas laminares se ven de perfil con un espesor aproximado de $50 \mathrm{~nm}$ y la terminación de las varillas es una pirámide con base hexagonal. En las imágenes de las figuras $23 \mathrm{c}$ y $23 \mathrm{~d}$ se muestran las distancias interplanares correspondientes en ambos tipos de partículas, los valores de la medición pertenecen al $\mathrm{ZnO}$ y se asigna a la familia de planos en la notación de índices de Miller. La aplicación de estas partículas puras y con dopantes en la detección de gases se señala en el artículo "Role of oxygen vacancies and in-doping on the sensing performance of $\mathrm{ZnO}$ particles" (Montes-Fonseca et al., 2017). Recientemente publicamos otras variantes en la morfología de estas partículas, en relación con su efectividad como material antifúngico: "Shape-dependent antifungal activity of $\mathrm{ZnO}$ particles against phytopathogenic fungi" (Pariona et al., 2020).

Hay muchos tipos de materiales nanométricos en estudio, espero que los ejemplos mostrados permitan entender la aplicación del MET en el estudio de nanopartículas, ya que esta es la base de la nanotecnología.

Figura 23. Morfologías del Zno: a) laminas; b) varillas y distancias interplanares de: c) laminas, y, d) varillas.
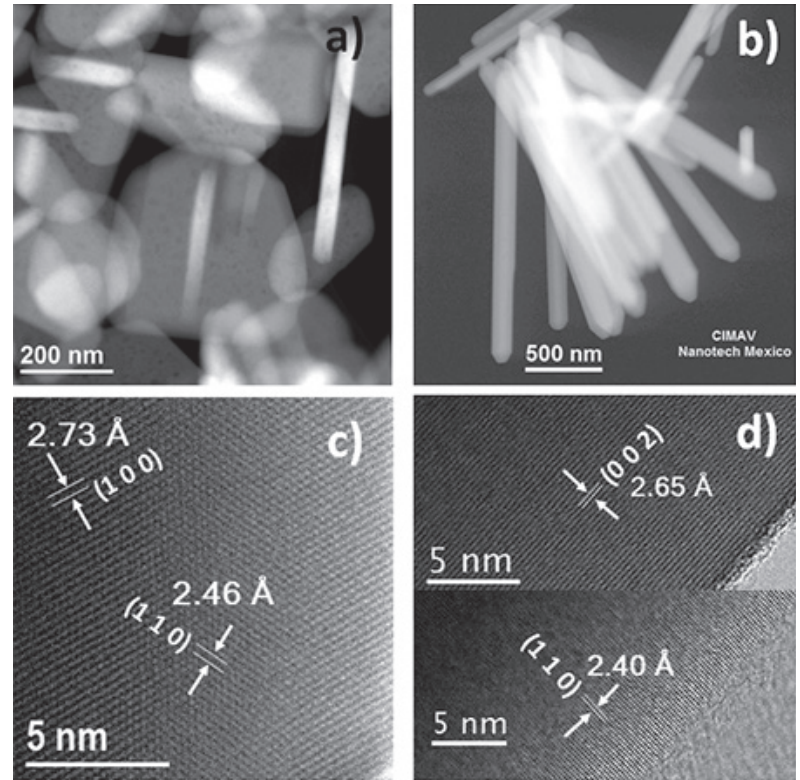

Fuente: Elaboración del autor, imágenes obtenidas en laboratorio CIMAV. 


\section{Conclusión}

Los microscopios electrónicos se deben usar según sea la necesidad para obtener resultados específicos del material. Cada instrumento tiene sus capacidades limitadas y los usuarios deben saber elegir el instrumento adecuado para obtener el resultado necesario, con la finalidad de caracterizar completamente el material en estudio. Es importante tener presente cómo ocurre la interacción del haz de electrones con la materia para poder interpretar adecuadamente las imágenes obtenidas.

Hoy en día, todos los microscopios comerciales tienen la opción de reconfigurar las lentes de acuerdo al interés del usuario para obtener resultados específicos, siendo esta una alternativa para hacer investigación en el estudio de las partículas nanométricas.

Es de gran importancia conocer a detalle las características del MET a usar, sus modalidades de trabajo y sus detectores, para obtener resultados experimentales en su máxima capacidad y no subutilizarlo.

Se mostró el estudio de varios nanomateriales como ejemplo en diferentes microscopios electrónicos con la configuración comercial y con la configuración específica de acuerdo con el interés del usuario. Aún quedan más opciones y variantes en la configuración de los tres equipos del CIMAV para hacer otros estudios específicos de los materiales.

Con los ejemplos presentados en este trabajo, los futuros usuarios del MET (estudiantes en el área de ciencia de materiales o nanotecnología) habrán obtenido elementos y criterios para abordar casos particulares en la interpretación de resultados experimentales procedentes de distintos microscopios.

\section{Referencias}

Barajas-Aguilar, A. H., Irwin, J. C., Garay-Tapia, A. M., Schwarz, T., Paraguay-Delgado F., Brodersen, P. M. y Sandoval, S. J. J. (2018). Crystalline structure, electronic and lattice-dynamics properties of NbTe2. Scientific reports, 8(1): 1-14. https://doi.org/10.1038/s41598-018-35308-4

Escobedo,Priscila Ivette. (2015). Optimización de parámetros geométricos en nanotubos de plata, tesis para ingeniero químico. Universidad autónoma de Chihuahua, México.

Espinosa Magaña, F. (2016). Laboratorio Nacional de Nanotecnología-CIMAV. Mundo Nano. Revista Interdisciplinaria en Nanociencias y Nanotecnología, 9(16): 157167.

Krishnamoorthy, K., Kim, G. S. y Kim, S. J. (2013). Graphene nanosheets: ultrasound assisted synthesis and characterization. Ultrasonics sonochemistry, 20(2): 644-649. https://doi.org/10.1016/j.ultsonch.2012.09.007

Malac, M., Beleggia, M., Taniguchi, Y., Egerton, R. F., y Zhu, Y. (2008). Low-dose performance of parallel-beam nanodiffraction. Ultramicroscopy, 109(1): 14-21. https://doi.org/10.1016/j.ultramic.2008.07.004 
Montes Fonseca, F., Olive Méndez, S. F., Holguín Momaca, J. T., Alonso Núñez, G. y Paraguay-Delgado, F. (2017). Role of oxygen vacancies and in doping on the sensing performance of $\mathrm{ZnO}$ particles. Physica status solidi c, 14(1-2): 1600226. https://doi.org/10.1002/pssc.201600226

Paraguay-Delgado, F., Malac, M., y Alonso-Nuñez, G. (2014). Structure and composition of single Pt-Ru electrocatalyst nanoparticles supported on multiwall carbon nanotubes. Materials Research Express, 1(4): 045026. https://doi.org/10.1088/20531591/1/4/045026

Pariona, N., Paraguay-Delgado, F., Basurto-Cereceda, S., Morales-Mendoza, J. E., Hermida-Montero, L. A., y Mtz-Enriquez, A. I. (2020). Shape-dependent antifungal activity of $\mathrm{ZnO}$ particles against phytopathogenic fungi. Applied Nanoscience, 10(2): 435-443. https://doi.org/10.1007/s13204-019-01127-w

Rubio-Ríos, A., Aguilar-Castillo, B. A., Flores-Gallardo, S., Hernández-Escobar, C. A., Zaragoza-Contreras, E. A., Zhao, Z., y Carpenter, M. A. (2012). Effect of synthesis variables on the fluorescence properties of CdSe-polystyrene látexes. Journal of Polymer Research, 19(3): 9833. https://doi.org/10.1007/s10965012-9833-5

Sato-Berru R. Y, Vasquez-Olmos A. R, Mejia-Uriarte E. V, Mata-Zamora M. E, SolisGomez A, Paraguay-Delgado F, Saniger J. M. (2018). Synthesis of silver colloids with a homemade light source. Journal of Cluster Science, 29(4): 719-724. https://doi.org/10.1007/s10876-018-1392-4

Tirado-Guizar, A., Pina-Luis, G., Paraguay-Delgado, F., y Ramirez-Herrera, D. (2014). Size-dependent enhanced energy transfer from tryptophan to CdSe/mercaptopropionic acid quantum dots: a new fluorescence resonance energy transfer nanosensor. Science of Advanced Materials, 6(3): 492-499. https://doi. org/10.1166/sam.2014.1742

Vásquez, F. C., Paraguay-Delgado, F., Morales-Mendoza, J. E., Antúnez-Flores, W., Lardizabal, D., Alonso-Nuñez, G., y Berhault, G. (2016). Shape and size controlled growth of $\mathrm{SnO} 2$ nano-particles by efficient approach. Superlattices and Microstructures, 90: 274-287. https://doi.org/10.1016/j.spmi.2015.12.014 
